\title{
Building Assets Toolkit: Developing Positive Benchmarks for Adolescent Girls-Instruction Guide [Arabic]
}

\author{
Judith Bruce \\ Population Council \\ Sarah Engebretsen \\ Population Council \\ Kimberly Glazer \\ Population Council
}

Follow this and additional works at: https://knowledgecommons.popcouncil.org/departments_sbsr-pgy

Part of the Family, Life Course, and Society Commons, Health Communication Commons, International Public Health Commons, and the Women's Health Commons How does access to this work benefit you? Let us know!

\section{Recommended Citation}

Bruce, Judith, Sarah Engebretsen, and Kimberly Glazer. 2016. "Building Assets Toolkit: Developing Positive Benchmarks for Adolescent Girls-Instruction Guide [in Arabic]." New York: Population Council. 


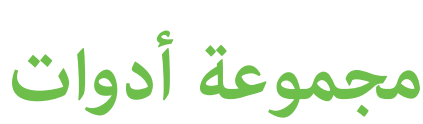

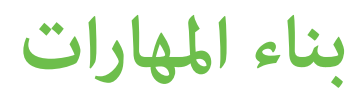

تطوير معايير

إيجابية للفتيات

اليافعات
المهارات الصحية

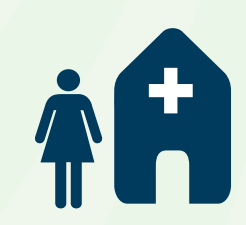

الأشياء التي تساعد على حماية حياة

الفتيات وحياة المحيطين بهن.

المهارات الاقثصادية

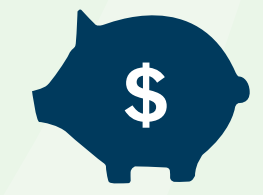

مهارات محددة تساعد الفتيات على التخطيط للمستقبل.
المهارات الإجتماعية

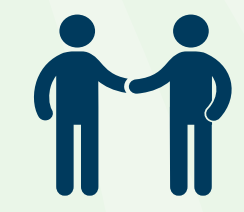

العلاقات الاجتماعية التي يمكن للفتيات الوصول إليها للمساعدة في الاستفادة من للفنات الفرص. - - الفي

\section{اكهارات الإدراكية}

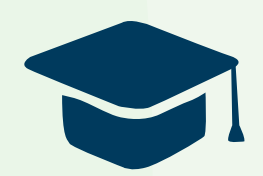

الكفاءات التي غالبا ما تنميها المدرسة (وبعد ألمدرسة نهوذجياً). 


\section{POPULATION COUNCIL \\ Ideas. Evidence. Impact.}

يواجه مجلس السكان قضايا صحية وإفائية حرجة - من وقف انتشار فيروس نقص المناعة البشرية إلى تحسين الصحة الإنجابية وضمان أن يعيش النشا

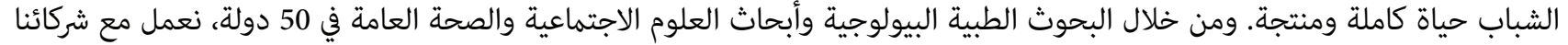

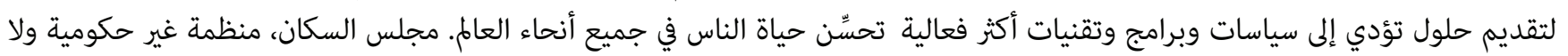
تبغي الريح، تأسست في عام 1952، مقرها في نيويورك ويديرها مجلس أمناء دولي.

Population Council

One Dag Hammarskjold Plaza

New York, NY 10017

popcouncil.org

هذه هي الترجمة العربية لهجموعة أدوات لتطوير بناء الههارات: تطوير معايير إيجابية للفتيات اليافعات، والذي سبق أن نشره مجلس السكان. ندعوك لإرسال ملاحظات وقصص عن كيفية استخدامك لهذه الهذه الأدوات.

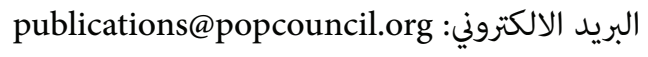

مراجع مقتَرَحة:

Bruce, Judith, Sarah Engebretsen, and Kimberly Glazer. 2016. "Building Assets Toolkit: Developing Positive Benchmarks for Adolescent Girls.” French translation. New York: Population Council. 


\section{مجموعة أدوات

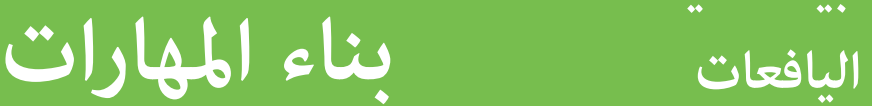 \\ تطوير معايير \\ إيجابية للفتيات}

تحتوي مجموعة أدوات بناء المهارات على:

دليل إرشادي خطوة بخطوة.

دليل موارد مع معلومات مهمة حول بناء محتوى برنامج هادف، موارد مفيدة لتعزيز تارين

بناءالمهارات، وملاحظات مفصلة عن كل مهارة.

مجموعة من 100 بطاقة مهارات. تتضمن هذه المجموعة أيضًا 12 بطاقة فارغة لإضافة مهارات بناءً على الطلب، وهو أمر نوصي به بشدة.

مجموعة من ثَاني بطاقات للأعمار (تتراوح من سن 6 إلى 20 عامًا) ، والتي نُظمت في ثلاث مجموعات ملونة للإشارة إلى المراحل الثلاث للمراهقة. 



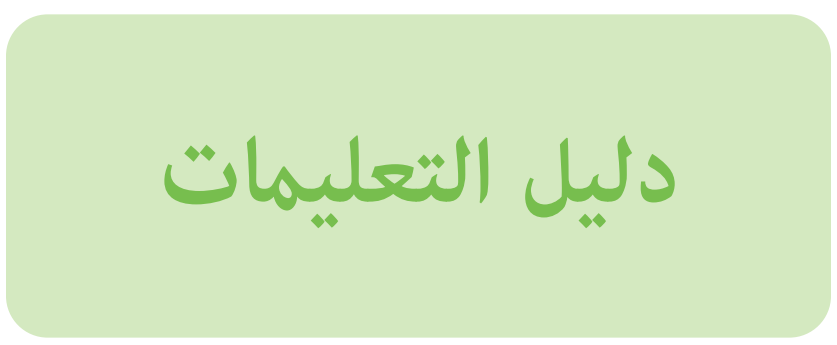

مجموعة أدوات بناء المهارات هي نهج لتطوير برامج لشرائح محددة من الفتيات والتي ستعدهن

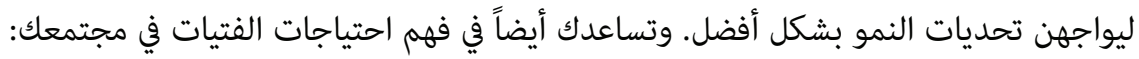

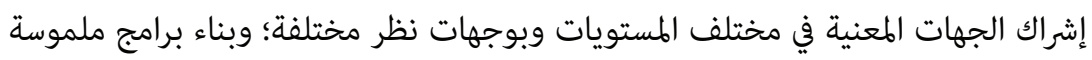
وهادفة للمراهقات. 


\section{تمرين بناء المهارات}

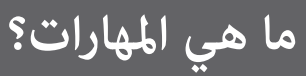

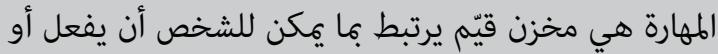

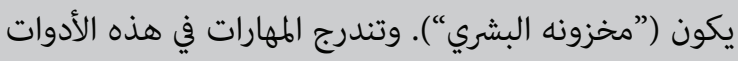

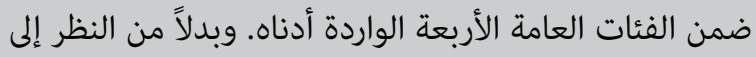

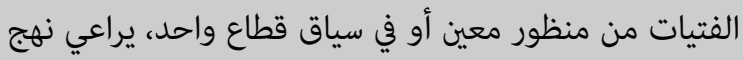

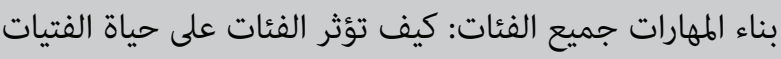
وكيف تتفاعل مع بعضها البعض.

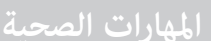

الأشياء التي تساعد على حماية حياة الفتيات وحياة

المحيطين بهن. المعرفة بالصحة الجنسية والإنجابية

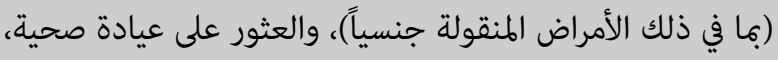

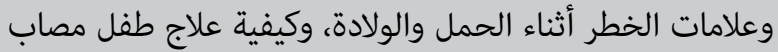
بالإسهال (للفتيات اللواتي يعتنين بأطفال أصغر سناً).

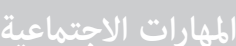

\section{العلاقات الاجتماعية التي يمكن للفتيات الوصول}

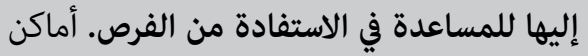

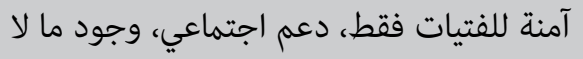

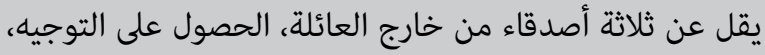

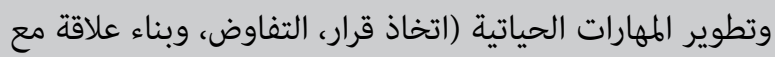

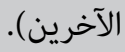

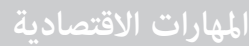

\section{مهارات محددة تساعد الفتيات على التخطيط}

للمستقبل. تعليم مالي مناسب للعمر/الصف، معرفة

$$
\text { كيفية إنشاء ميزانية بسيطة (و إنشاء حساب توفير صغير)، }
$$

as goyl توإlatol

الكفاءات التي غالبا ما تنميها المدرسة (وبعد

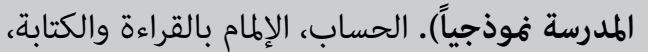
الثقة والتعبير الواضح عن الذات، التحليل النقدي، التواصل، وحل | 1لششاكل.
هذه الأدوات تحتوي على جميع المواد التي

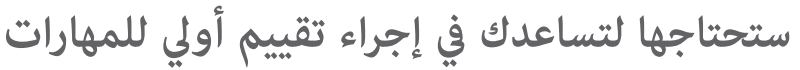

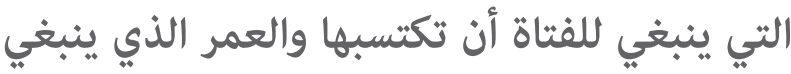
أن تكون فيه قد اكتسبت هذه المهارات.

إن عملية بناء المهارات هي نهج مدروس لبناء محتوى برنامج

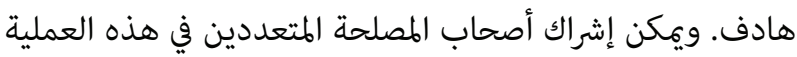
التي صُممت لتحديد المهارات التي تحتاج إليها الفتيات من أجل ألماتل

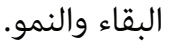

في مرحلة بداية التمرين، نفترض أنك: • • قررت بالفعل أنه من المهم العمل مع الفتيات.

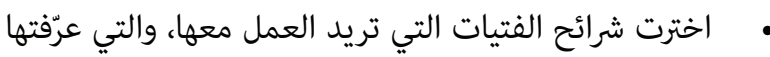

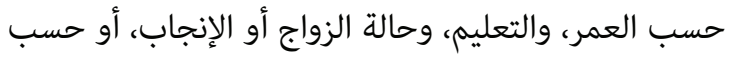

شرائح فريدة في منطقتك، مثل عاملات المنازل المهاجرات التهات

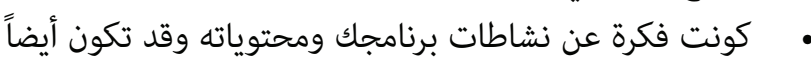
"ورثت" مواداً غير كافية من برامج أخرى.

\section{فوائد تمرين بناء المهارات}

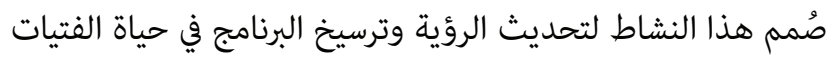
الفعلية ولتحديد أولويات المحتوى لفئات السكان التي تستهدفها.

فعلى سبيل المثال، قد ترغب في تضمين الصحة الإنجابية ولكنك

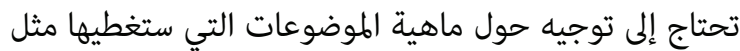

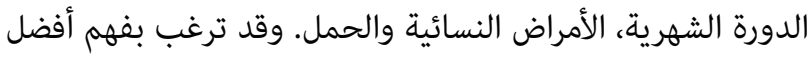
للمهارات الرئيسية اللازمة لاستخدام هذه المعلومات.

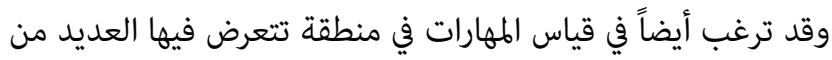
الفتيات لمهارسات خطرة مثل التسرب من المدرسة أو الزواج المبكر.

من المهم أن تكون منفتحًا عندما يتعلق الأمر بأنشطة البرنامج

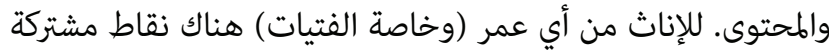
بين المهارات الصحية والاجتماعية والاقتصادية والإدراكية (انظر إلى إلى

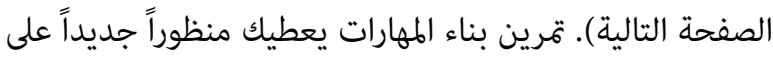

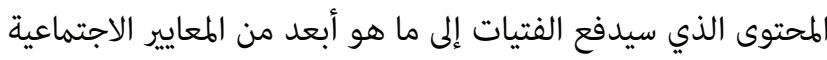

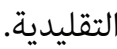




\section{بلدء التمرين}

بطاقات هذه المجموعة تعدد المهارات التي تستطيع المراهقات

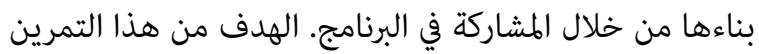

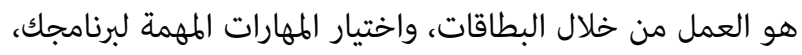

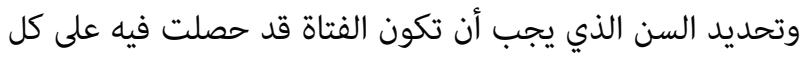

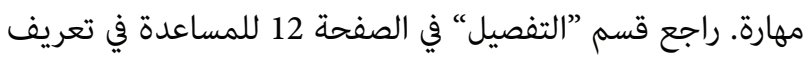

شريحة الفتيات التي تريد العمل معها والكهارات التي ستكون

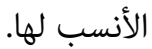

\section{للبدء، ثبّت إشارات العمر (سن 6، 8، 10، 12، 14، 16، 18، 20) على جدار أو سطح مستو آخر. الهدف إن الهار الهن}

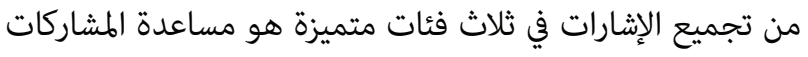

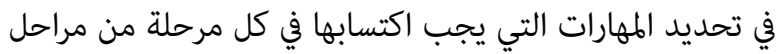

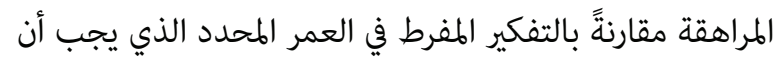
تحصل فيه الفتاة على كل مهارة.

\section{مع كامل مجموعتك، اختر بعض المهارات وادعُ}

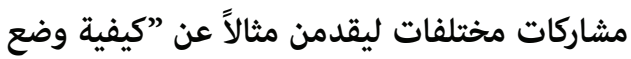

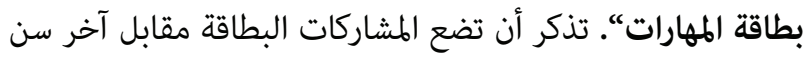

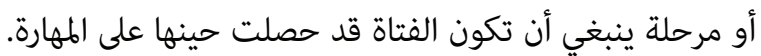

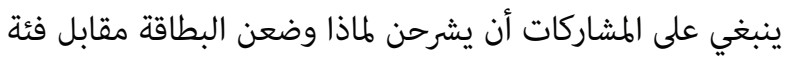

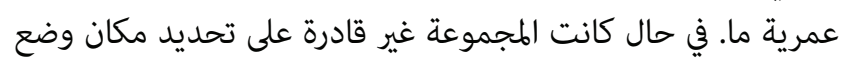

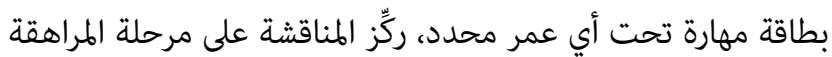
المناسبة لهذه المهارة في رأيهن.

بعد أن تتأكد من أن الجميع فهم التمرين، ابدأ بتقسيم

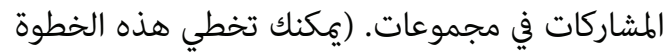

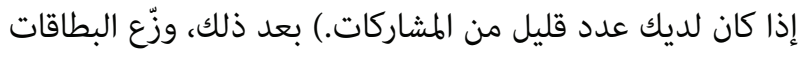

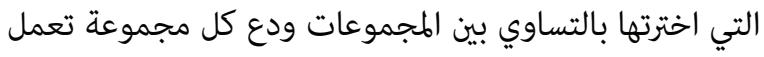
بشكل مستقل. ينبغي على المشاركات قراءة كل بطاقة من مجموعة

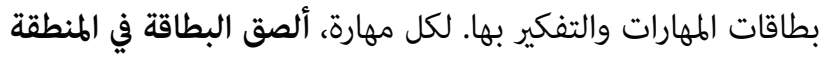
تحت إشارة العمر الذي ينبغي للفتاة الحصول على المهارة فيه.

لا تشعر أن عليك استخدام كل المهارات في مجموعة البطاقات؛

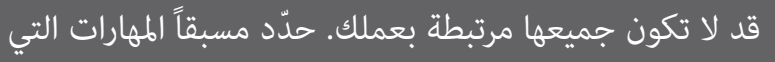

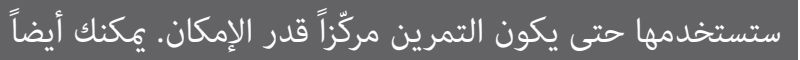

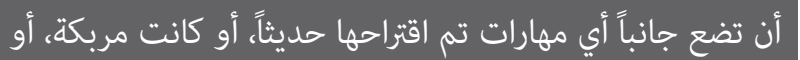
مسببة للجدل. هذه البنود ستتطلب المزيد من المناقشة.

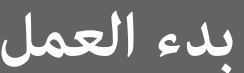

ستستخدم المواد التالية:

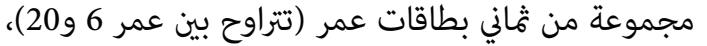

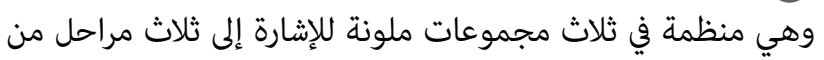

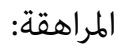

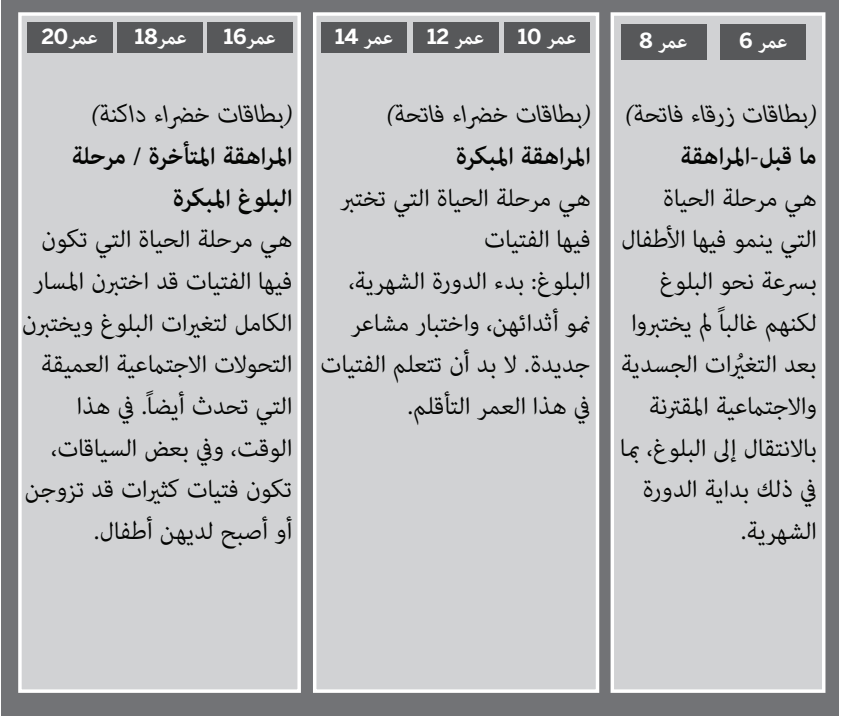

مجموعة من 100 بطاقة مهارات. أختيرت البطاقات المضمنة

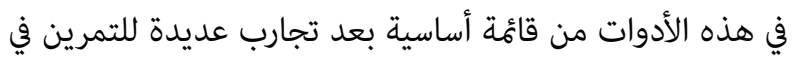

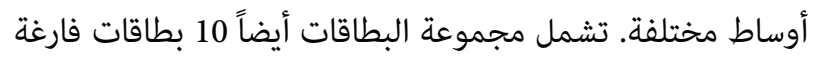
لإضافة مهارات حسب الطلب، وهو أمر مُشَجَع.

دليل الموارد الذي يوفر معلومات مهمة عن بناء محتوى برنامج

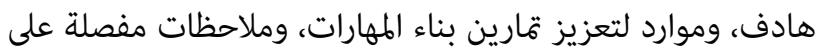

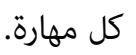

احرص على قراءة دليل الموارد قبل بدء التمرين. إذا كنت ترغب

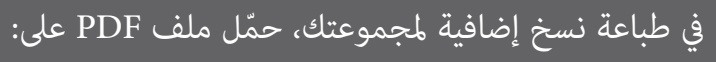

popcouncil.org/AssetToolkit

ستحتاج إلى تقديم شريط لاصق

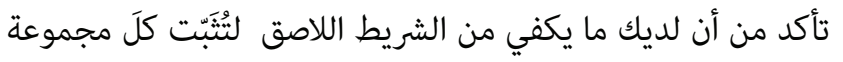

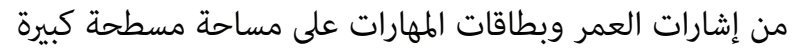

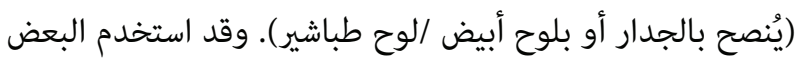
الأرض أو الطاولات في حال عدم توفر شريط لاصق.

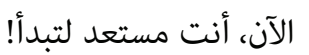


حذّد السن الأقصى الذي يجب أن تكون فيه الفتاة قد اكتسبت مهارة معينة

حين تبدأ بوضع المهارات (أو تحريكها)، ستميل إلى مقارنة المثالي مع العا

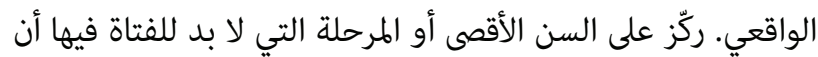

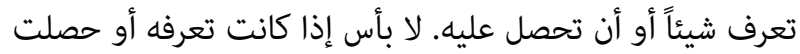
عليه قبل ذلك، ولكن في ظل الظروف الحالية (مهما كانت صعبة)، في أي عمر يجب أن تعرف ذلك؟ مناقشة الحقائق التي تواجهها

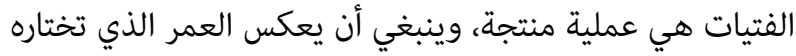

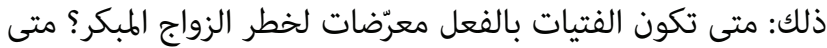

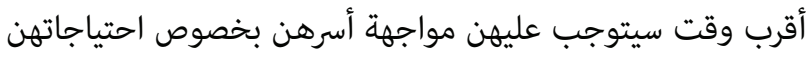
الذاتية (الشعور بالجوع، التعبير عن حقوقهن، وإيجاد طرق لإدارة

في حال بدى المحتوى صعباً بعد الجولة الأولى، اطلب من المشاركات

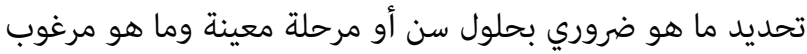
فيه. في هذه العملية، قد تركز أكثر على المحيط والشرائح المختلفة

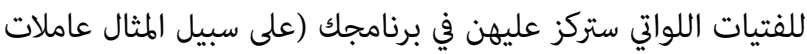

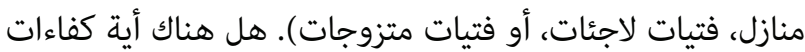

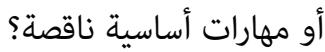

\footnotetext{
دراسة حالة هناك حاجة إلى بعض الههارات في وقت أبكر مما تعتقد

في غرب أفريقيا، أفادت مجموعة من ممارسي البرامج الذين أجروا

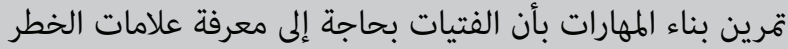

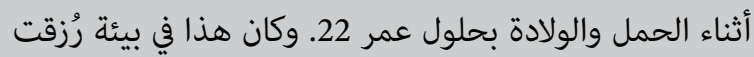

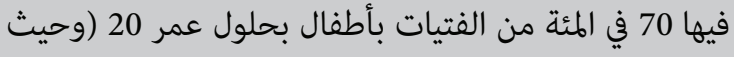
كانت هناك تصورات كامنة بأن تعليم الفتيات عن الصحة الجنسية والإنجابية من شأنه أن يشجع على كان تعليم الفيات عارسة علاقات الصحة

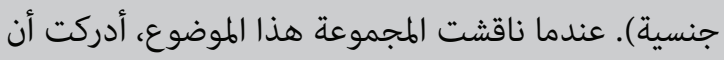

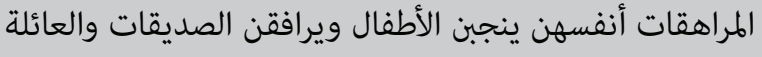

بعد أن وضع الجميع مهاراتهم، تمعنوا في النتائج وأجيبوا

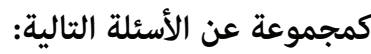

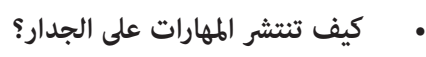

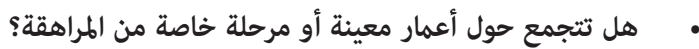

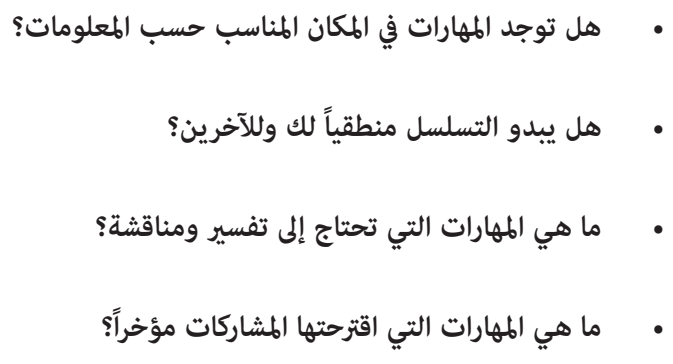

لا شك أنه ستكون هناك مهارات غير مدرجة في المجموعة لكنها

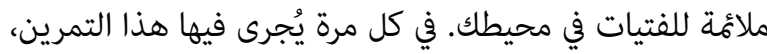

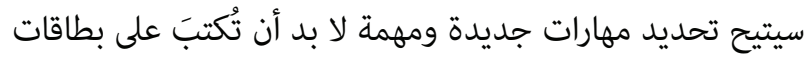

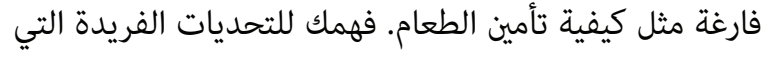

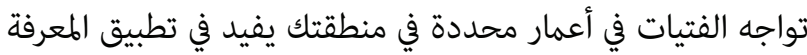
والكهارات لمواجهة هذه التحديات.

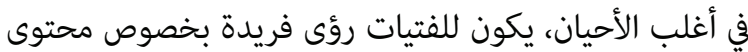

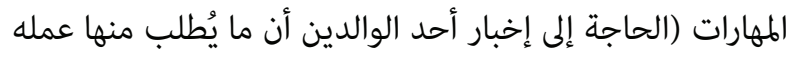

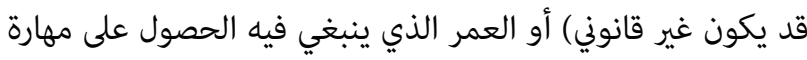

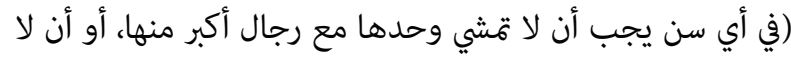

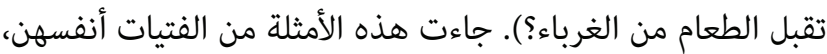

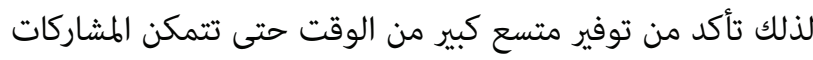
من تطوير مهاراتهن الخاصة ووضعها تحت الفئة العمرية المناسبة. 


\section{الإنتقال من اختيار الكهارات

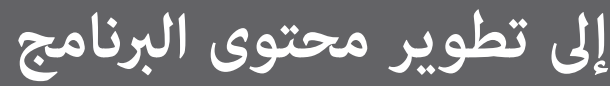

في يوم واحد (أو أقل) يمكنك وضع قائمة بالمهارات حسب الشريحة

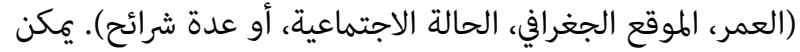

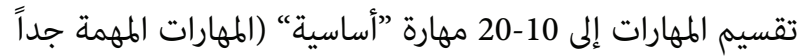

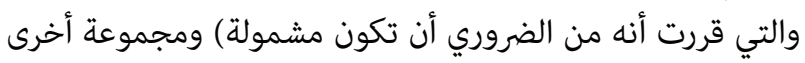

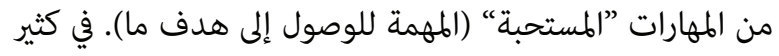

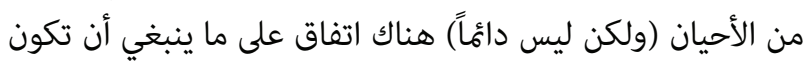

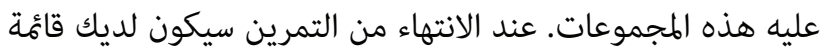

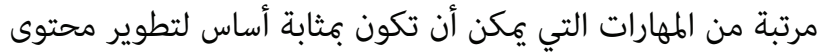
برنامجك.

مجموعة الأدوات هذه تحتوي على ورقة تخطيط برنامج تفيد في

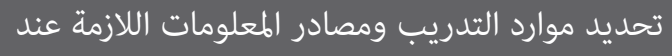

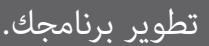

أثناء الولادة. لذا، بغض النظر عن التحيزات الفردية، كان من

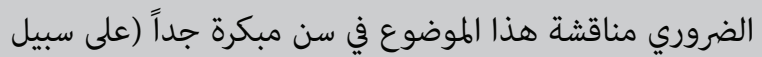

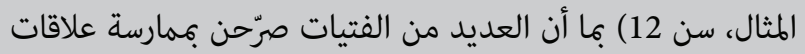

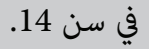

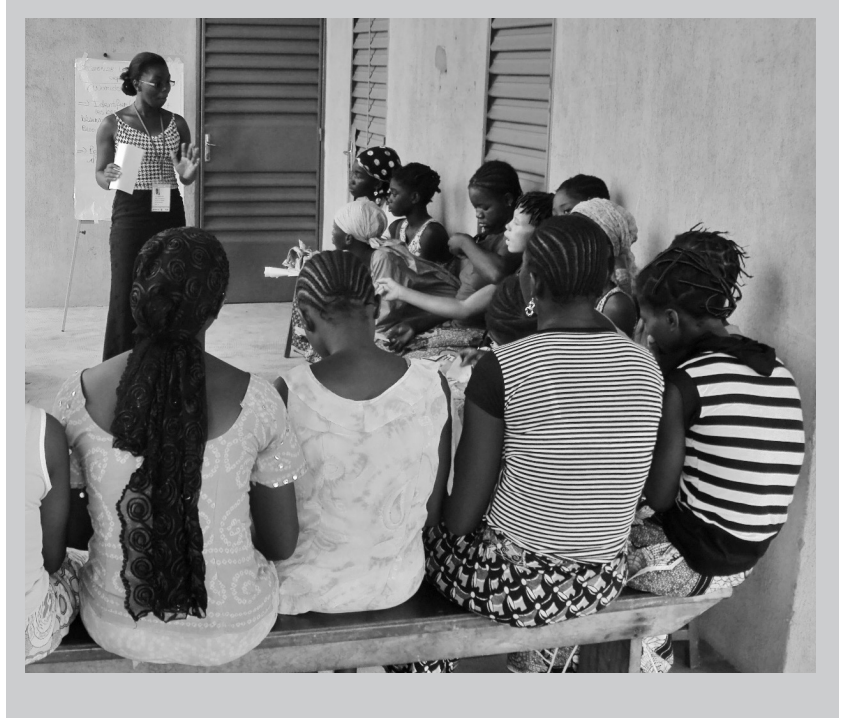

\section{تزمصل}

قد تُجري هذا التمرين وفي تصورك فئة معينة من الفتيات. هذا قد

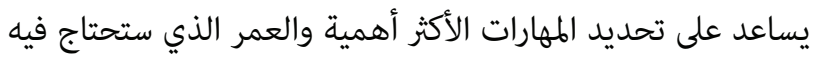

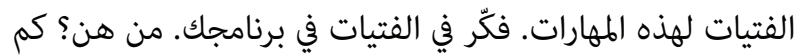

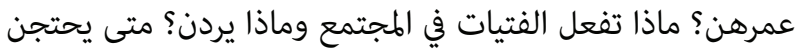

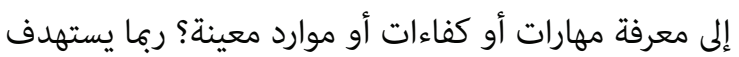

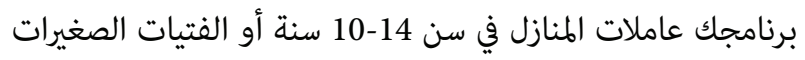
اللواتي لديهن أطفال. هل هناك مهات المارات فئنات مهمة جداً لهذه الشريحة

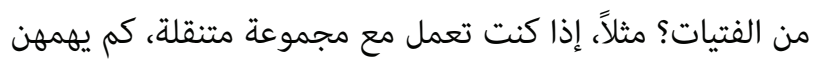

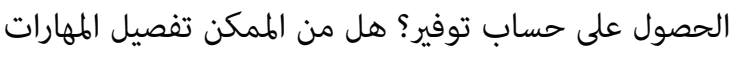

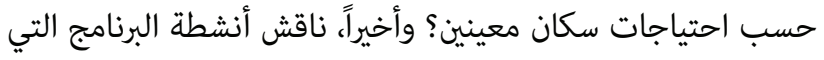

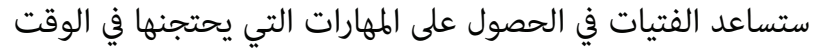
الذي يحتجن فيه إلى هذه المهارات. 

دليل الموارد 
المهارة هي مخزن قيّم مرتبط مـا يككن لشخص أن يفعله أو يكونه ("مخزونه

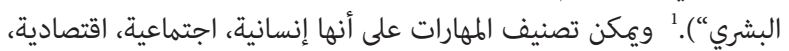

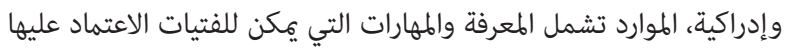
لصقل حياتهن والتعامل مع حالات الطوارئ بأنفسهن أو نيابة عن المنات الآخرين.

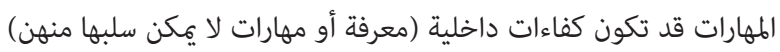

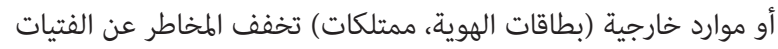

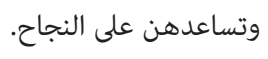

وقد تتعدد أهداف المهارة الواحدة، فمثلاً، الادخار هو مهارة مالية تستخدم

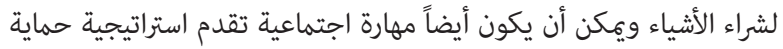

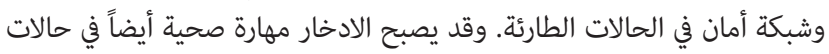

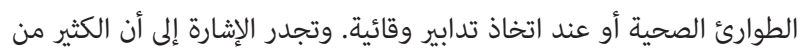

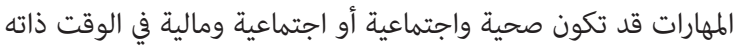
Austrian and Muthengi 2014). ${ }^{2}$

\section{التركيز على المهارات هو تركيز على الإيجابيات}

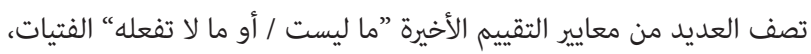

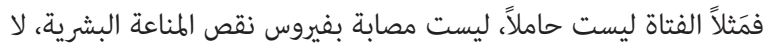

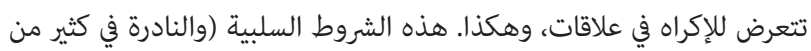

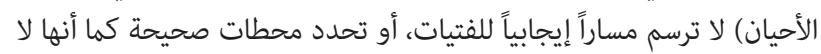

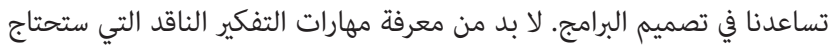

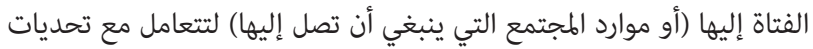

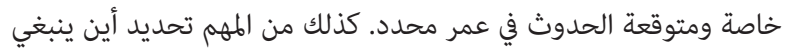

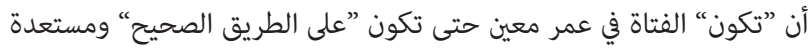

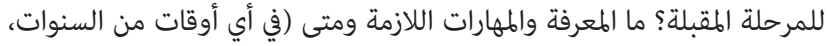

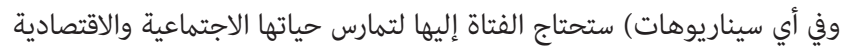

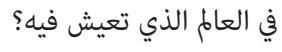

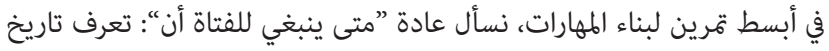

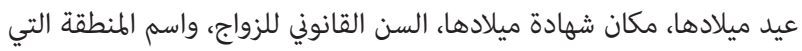

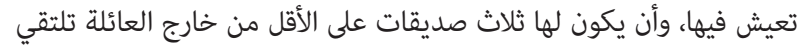

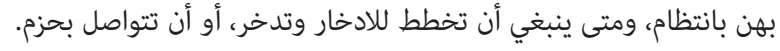

المهارات ملموسة وإيجابية ويكن ترتيبها في جدول زمني وفي أماكن محددة،

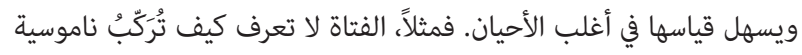
على السرير في الوقت 1، لكنها تعرف كيف تقوم بذلك في في الوقت 2 (ولا أحد

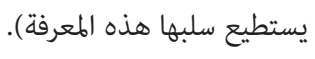

قامت كل من جوديث بروس، سارة إنجيبرتسن، وكيمبرلي غلايزر بتطوير أدوات

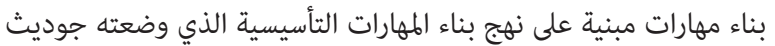
بروس وجينيفر سبستاد (مجلس السكان 2005). وساهمت كل من من كارين المارين

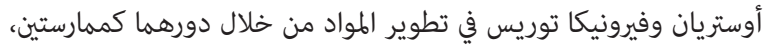

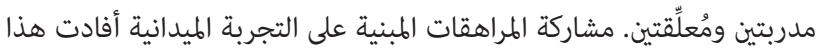

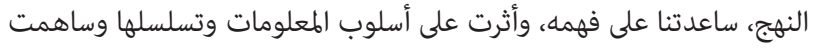

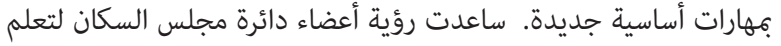

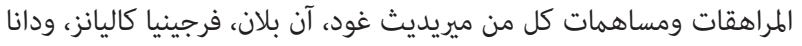

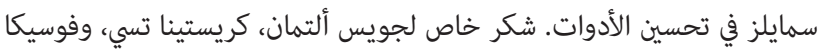

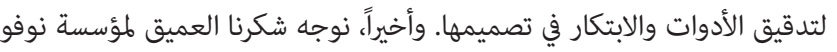
لإعطائهم الأولية لبرامج ملموسة للفتيات وللاعتراف بأهمية الأدوات الميدانية.

\section{بناء محتوى برنامج هادف}

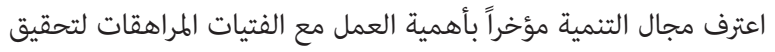

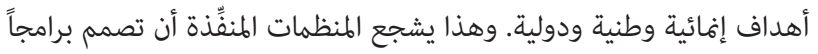

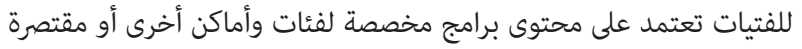

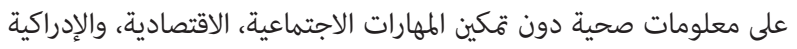
اللازمة لضمان صحة الفتيات وحقوقهن وتأمين فرص اجتماعية واقتصادية الإية أوسع والادراية لهن.

"تمرين بناء المهارات" هو نهج مدروس لبناء محتوى برنامج هادف. التمرين

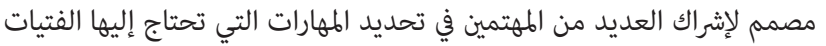

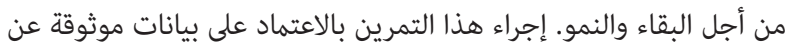

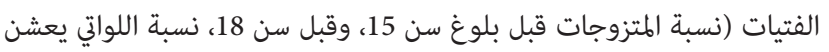

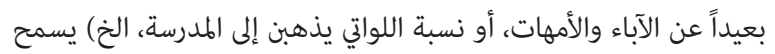

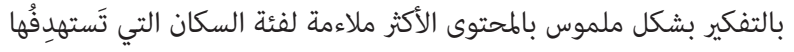
;Bruce and Hallman 2008; Austrian and Ghati 2010) (designingforscale.popcouncil.org على سبيل المثال، قد يقلقك ارتفاع معدل الحمل لدى المراهقات بما أن الفتيات

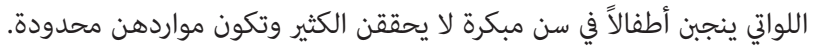

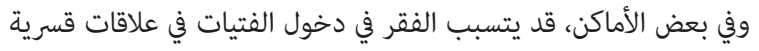

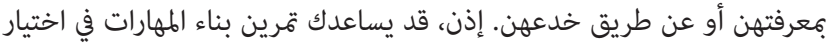

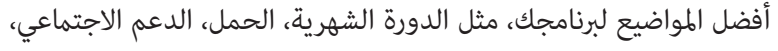

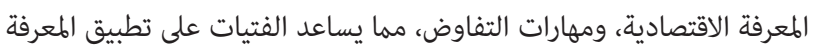

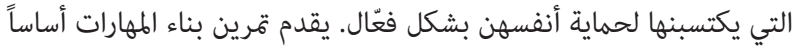

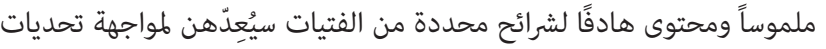

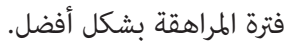

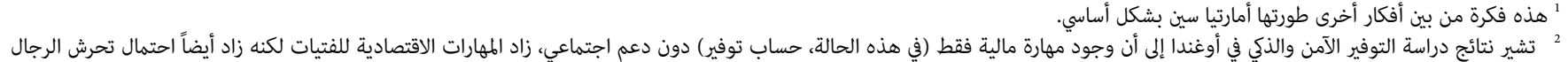

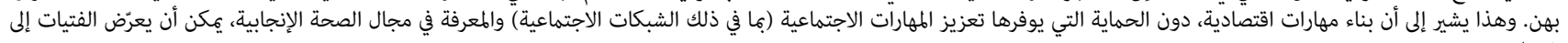


مع الأشخاص، وسيساعدها على الاستعداد للتدريب المهني مثل الفتيات الأكبر سنًا.

انتقال الفتيات من التعرض إلى أخطار كبيرة إلى التعرّض لأخطار أقل لا يسير في

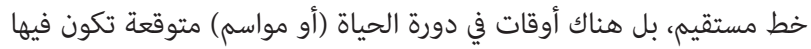

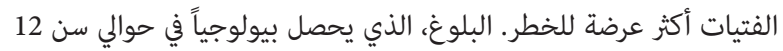

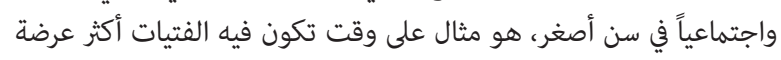

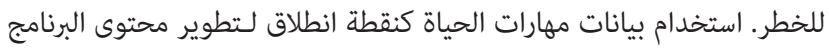

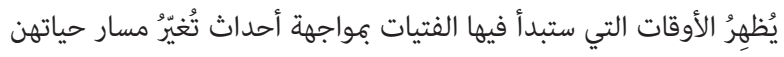

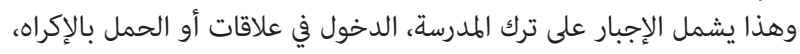

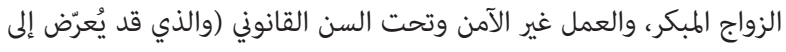
تعنيف). وهذا لا يتطلب أن يكون لدى الشخص أي أي خبرة في البيانات.

”أدلة بيانات المراهقين“3 توفر إطاراً أساسيًا لأي شخص يرغب في معرفة الأوقات

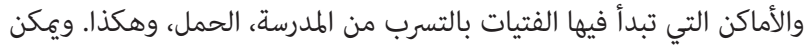

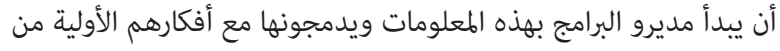

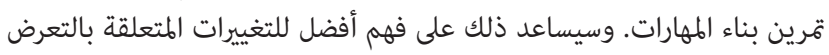

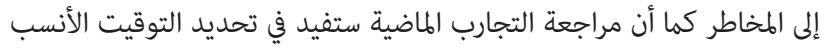

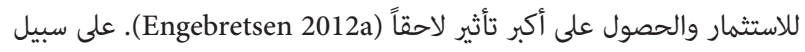

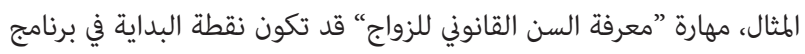

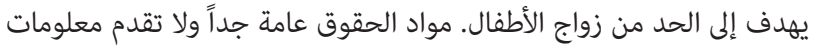
محددة حول كيفية تحديد سيناريوهات المخاطر والتعامل معها. فمثلاً، نحتاج

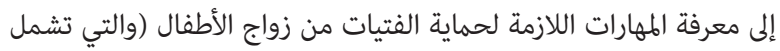

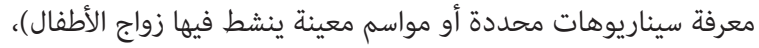

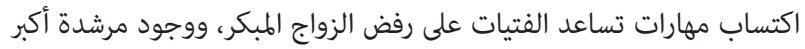

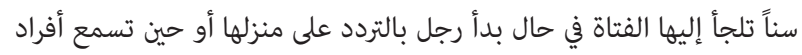
الأسرة يناقشون إخراجها من المدرسة مثلاً (Bruce 2012).

\section{تركيز التمرين الذي تُطَورُه لبناء الطهارات}

سيبدأ التمرين بعد اتخاذ بعض القرارات الرئيسية للبرنامج، مثل التدخل في المناطق التي تكثر فيها الفتيات المعرضضات للخطر النرات (Engebretsen 2012b).

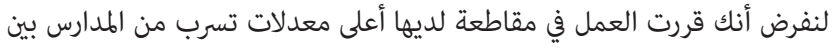

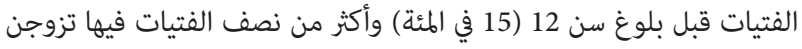

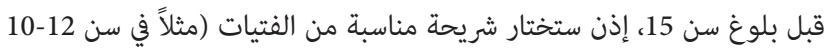
سنة خارج المدرسة أو تأخرن عن صفين دراسيين على الأقل، واللواتي تزوجن أنسات

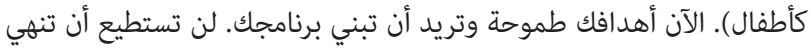

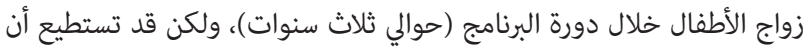

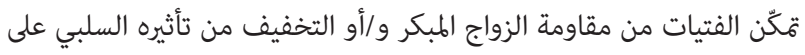

الفتيات المتزوجات (Erulkar and Muthengi 2008). تقدم عملية بناء المهارات ”رؤية جديدة، لبرامج الفتيات وتُشرِكُ الجهات المهتمة

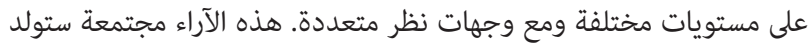

\section{التزكيز على بناء المهارات يأخذ في عين الاعتبار الحقائق والبيانات وتطلعات الفتيات}

نهج بناء المهارات ضروري جداً في البرامج التي تهدف إلى الوصول إلى أفقر

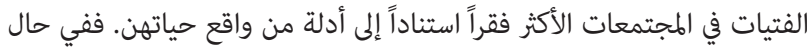
وجود نسبة عالية من الفتيات اللواتي سيصبحن أمهات عازبات ويتات وينجبن أطفالاًاً

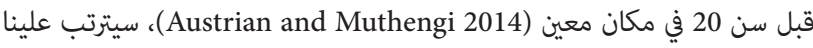

أن نبني مهارات حماية للفتيات تساعدهن على البقاء في المدرسة، ومقاومة

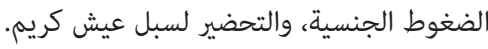

تساعد المهارات الفتيات على التعامل مع مخاطر حقيقية في حياتهن، مثل ندرة

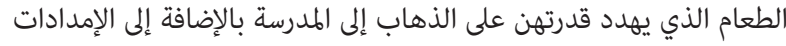

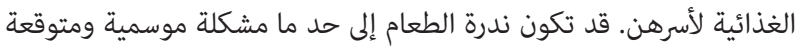

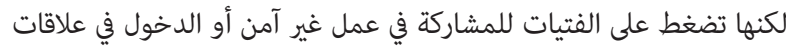

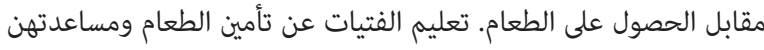

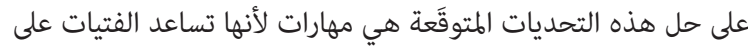

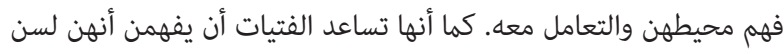

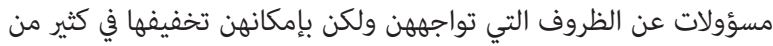

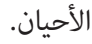

نحن نعتمد على حصيلة البيانات والتجارب الحياتية للفتيات وعلى الذين

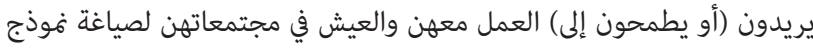

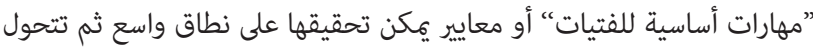

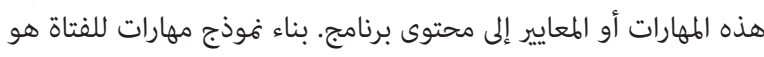

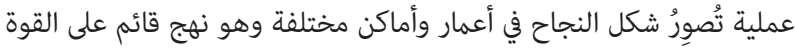

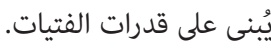

\section{الفتيات يكتسبن المهارات على عدة مراحل (عمرية} عادةً)

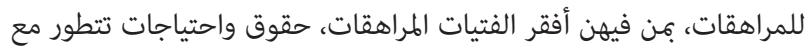

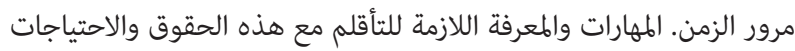

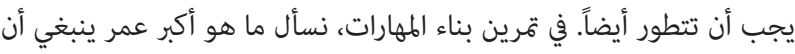

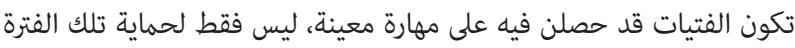
من حياتهن ولكن للتحضير للمرحلة القادمة.

في معظم الأماكن في العالم، وخاصة في أفقرها، الفتيات يحتجن إلى الاستعداد

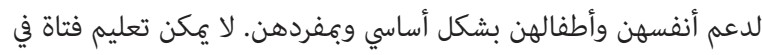

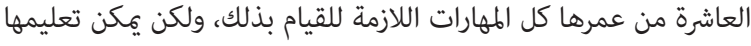

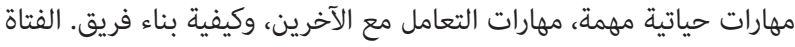

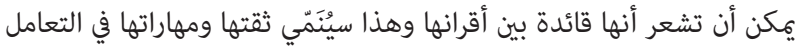

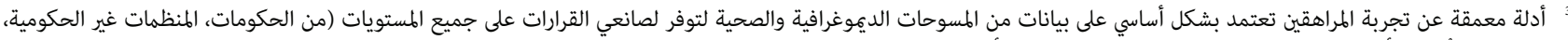
popcouncil.org/adolescentdataguides ومجموعات المنُاصَرة) أدلة عن حالة المراهقات من سن المرات 
أوقات المخاطر والتحديات؟ وماذا يحق لهن أن يعرفن؟ فمثلاً في هايتي،

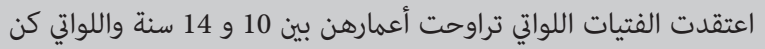

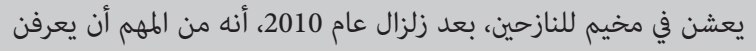

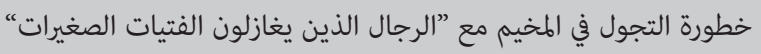

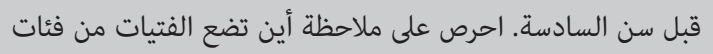

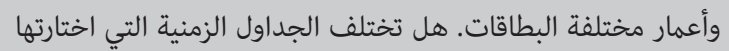

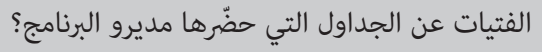

\section{استخدم المهارات المُختارةة لإعلام محتوى البرنامج}

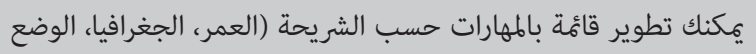

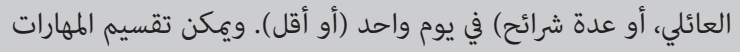

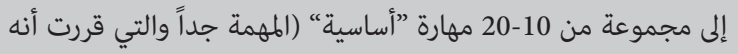

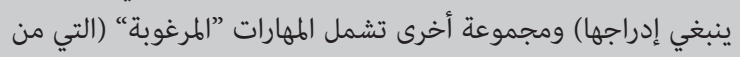

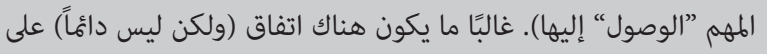

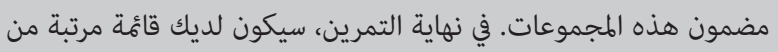
المهارات الأساسية لتطوير محتوى برنامجك.

\section{قيّم المواد اللازمة لتقديم الههارات}

حين تطابق المهارات مع المواد المحتملة، ستحتاج أولاً لتقييم المواد

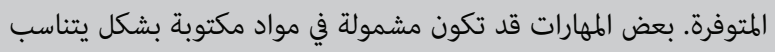

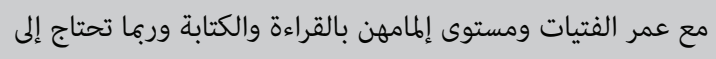

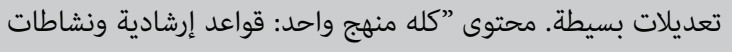

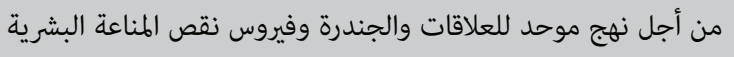

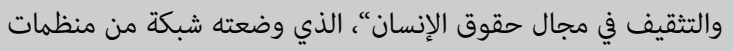

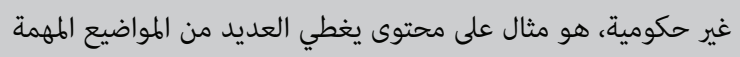

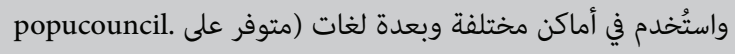

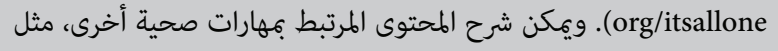
تعليمات حول علاج الجفاف عن طريق الفم واستخدام ناموسيات السرير

$$
\text { للفتيات بسهولة. }
$$

قد تتطلب بعض المواد الأخرى تعديلات أكثر حسب مستوى القراءة،

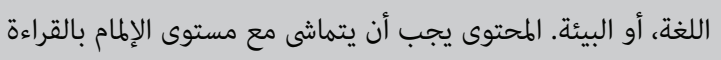

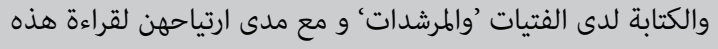

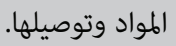

المواد المتاحة حسب مستوى القراءة للفتيات المتعلمات اللواتي تتراوح

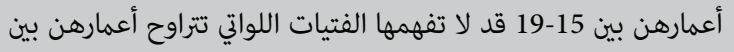
10-14 أو المرشدات فين بعض الأماكن. وبالإضافة إلى ذلك، بعض الفرات الفئات

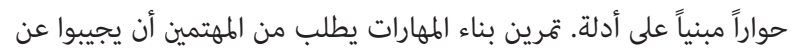

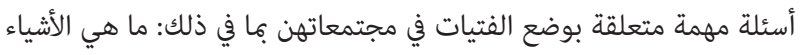

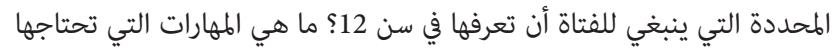

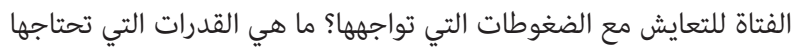

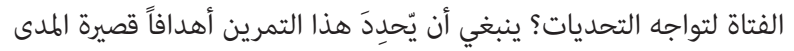

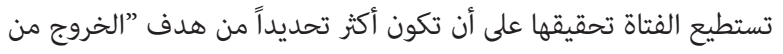

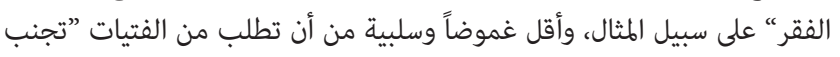

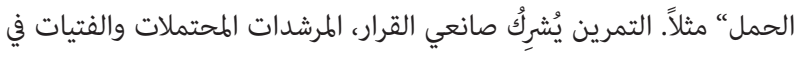

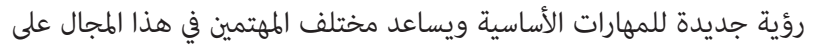

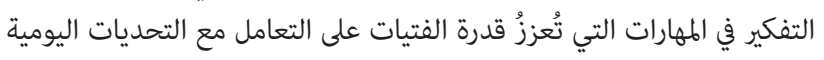
والفرص ويساعد على اختيار المحتوى الأنسب للبرنامج.

\section{احترم موظفي البرنامج وصانعي السياسات و تحدّاهم}

الموظفون المستقبليون (بمن فيهم المرشدات في بعض الحالات) هم المفتاح.

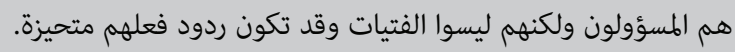

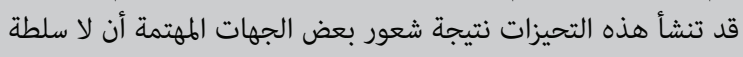

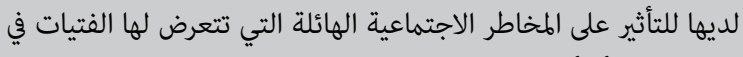

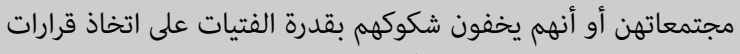

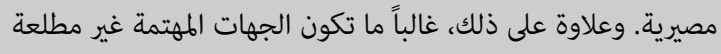

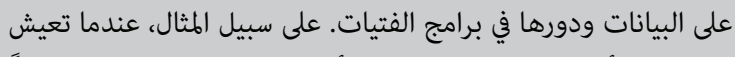

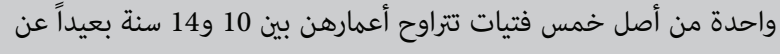

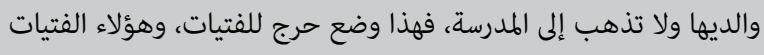

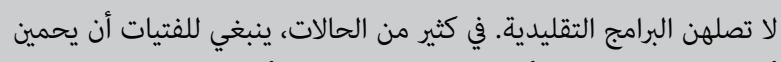

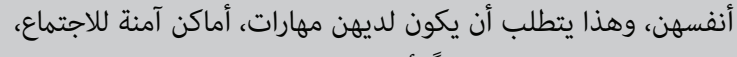
وقدرة على المشاركة اقتصادياً بأمان.

هذا التمرين يذكّر جميع المهتمين بالحقائق. وهو يشمل تخطيطًا ملموسًا

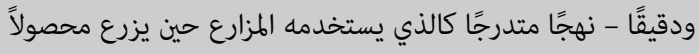

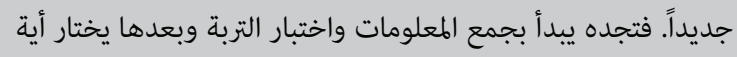

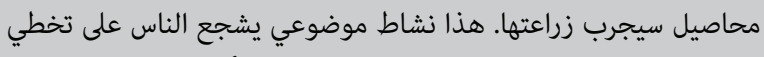

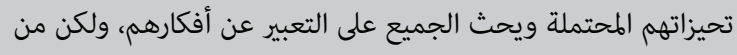

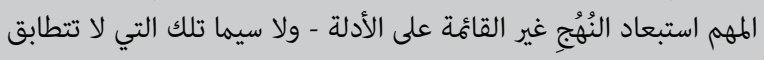

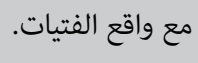
أَشْرِكْ الفتيات

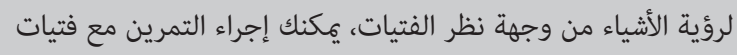

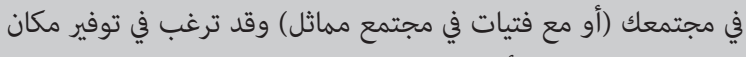

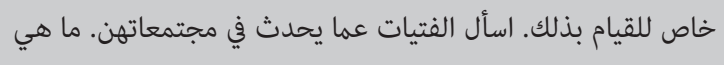


بتقديم محتوى حول محو الأمية المالية بدلاً من أن تنشر الفتيات

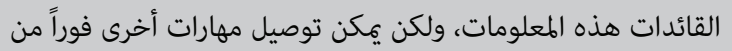
خلال ألعاب تلعبها الفتيات معًا.

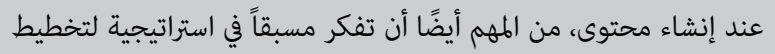

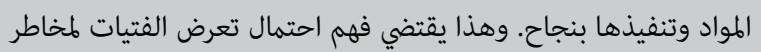

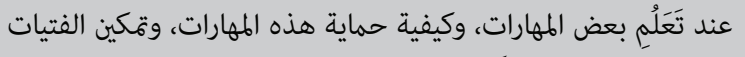

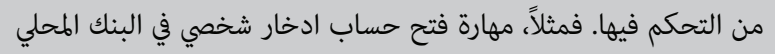

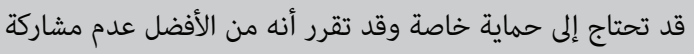

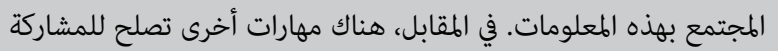

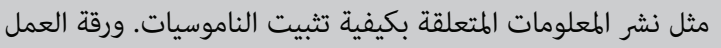

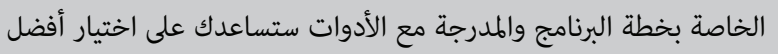
المواد والموارد التي تعكس قائة المهارات الأساسية في مواد لبرنامجك.
السكانية قد تكون ملمة بالقراءة ولكنها لم تتعود على تلقي المعلومات

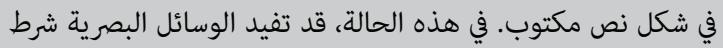

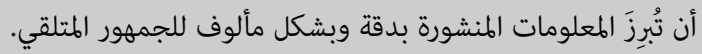

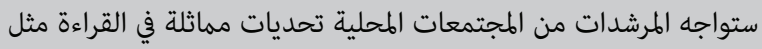

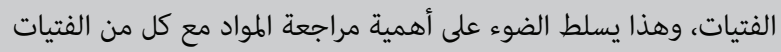

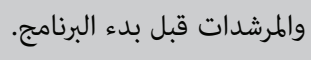

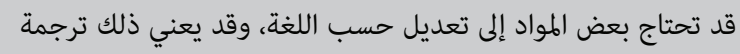

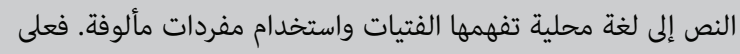

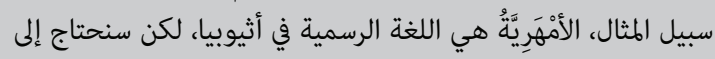

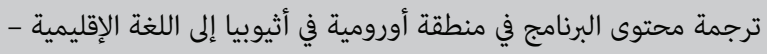

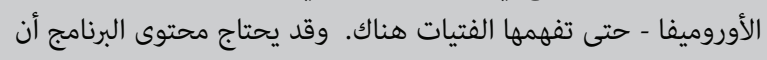

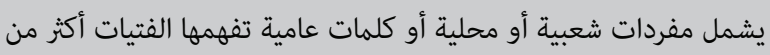

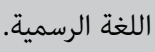

بالإضافة إلى ذلك، قد تحتاج إلى تكييف بعض المواد لتناسب المكان.

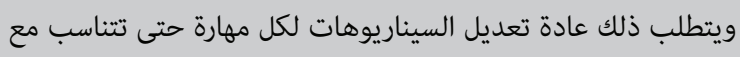

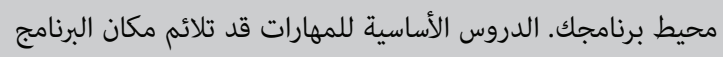

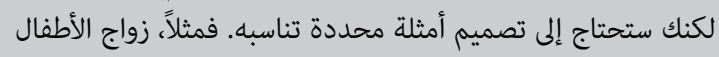

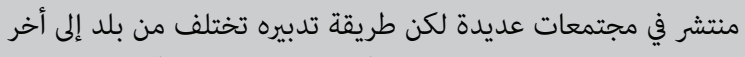

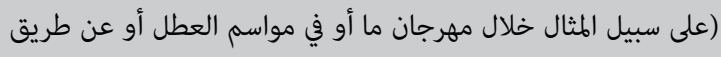

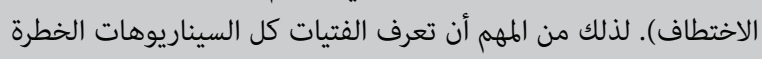
في مجتمعهن.

قد لا يتوفر المحتوى لبعض المهارات وعندها ستحتاج إلى تحضير مواد

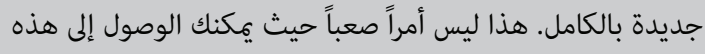

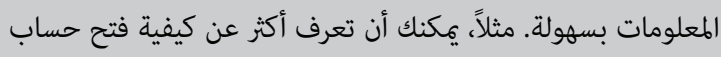

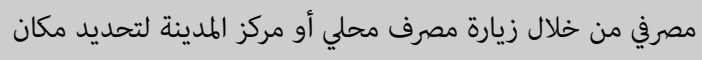

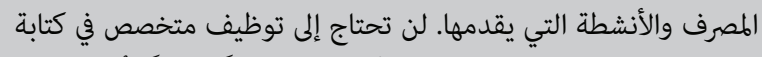

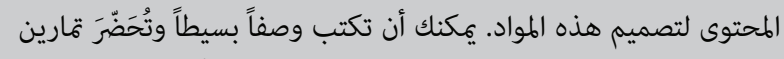

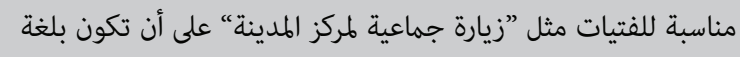

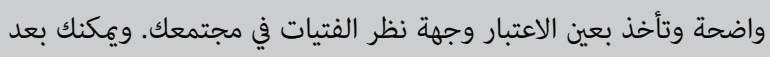
ذلك اختبار المواد مع الفتيات وتقييم فهمهن للمعلومات وتنات وتنقيحها وفقًا

لذلك.

عند تكييف المواد وتطوير مواد جديدة، سترغب في النظر في آليات

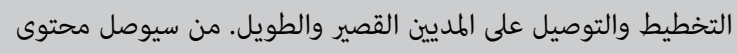

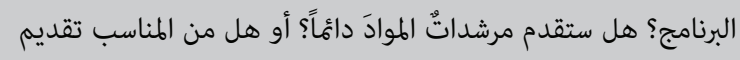

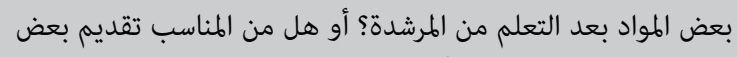

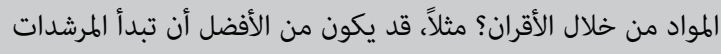


4. يكون لديها مكان للقاء الأصدقاء بأمان وبخصوصية على الأقل مرة واحدة

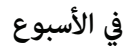

عند اقتراب سن البلوغ، قيل الفتيات إلى العزلة ويجدن صعوبة في الوصول

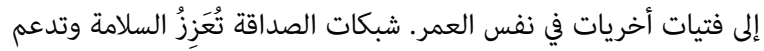

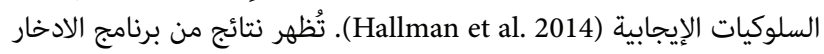

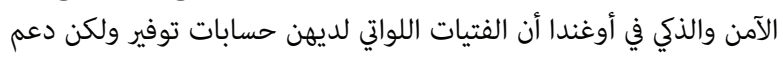

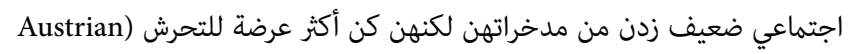
and Muthengi 2014

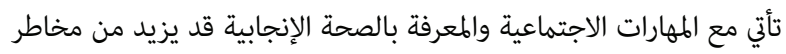

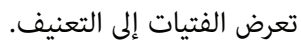

المرجع: (Hallman 2011)

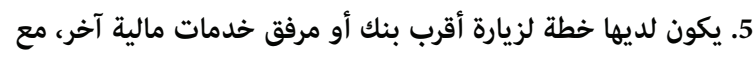
الأصدقاء أو أحد الوالدين

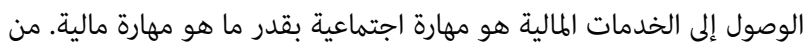

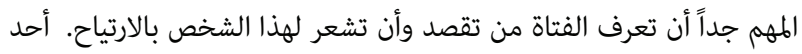

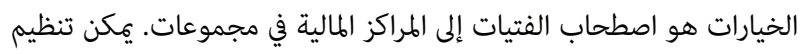

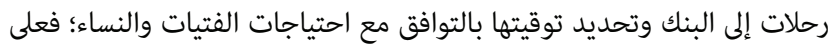

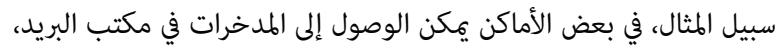

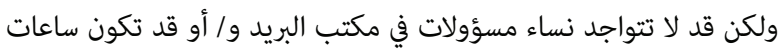

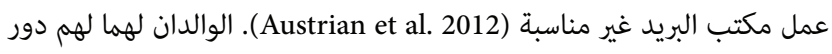
أساسي في تسهيل الوصول إلى المؤسسات المالية من خلال سلوكهما الشخصي.

6. تعرف مكان أقرب مركز شرطة ونوع المساعدات التي يمكن أن يوفرها

يمكن أن تكون مراكز الشرطة مصدراً للمساعدة، ولكن ينبغي للفتيات أن يطلبن

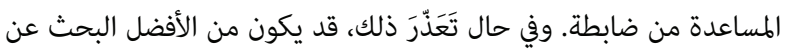

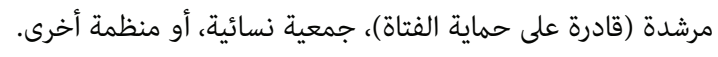

المرجع: (2013 del Valle و2014)

\section{7. تعرف علامات الإسهال لدى الطفل وكيفية علاجها}

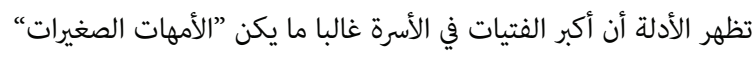

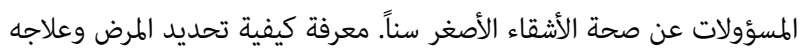
أمر مهم لصحة العائلة وتعزيز المعرفة الصحية للمجتمع بأكمله.

\section{8. تعرف من أين تحصل على فحص فيروس نقص المناعة البشرية}

ينبغي أن تعرف الفتيات كيفية انتقال فيروس نقص المناعة البشرية واحتمال

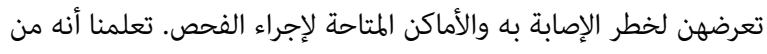

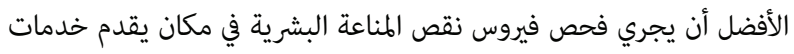

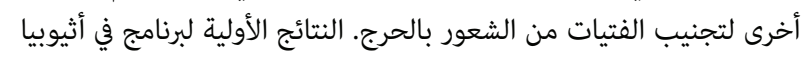

\section{موارد ومعلوماث مفيدة عن مهارات معنية}

لقد جمعنا تعليقات وموارد مفيدة لكل مهارة مدرجة أدناه. ونوصي أن تراجع

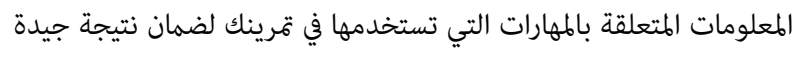

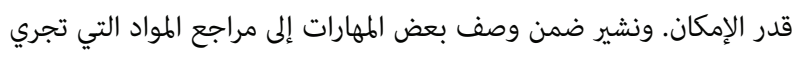

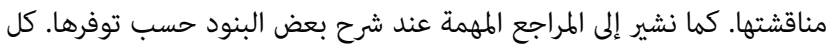
المراجع موجودة في الصفحة 64. ما هو أكبر عمر أو آخر مرحلة ينبغي للفتاة حينها أن ....

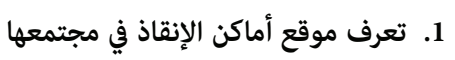

لكي تكون الفتاة آمنة، يجب أن يكون لديها خطة أمان محددة تشمل معرفة إلى مدان

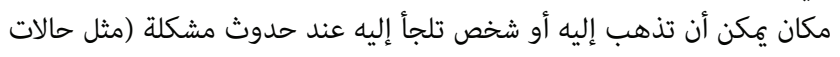

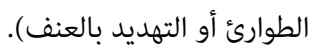

2. تعرف موقع أقرب مركز خدمات صحية طارئة حالتين على الأقل ثتطلبان عناية ضرورية

معرفة مراكز الخدمات الصحية الطارئة والوصول إليها تزيد من احتمال نجاة

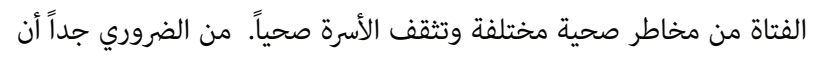

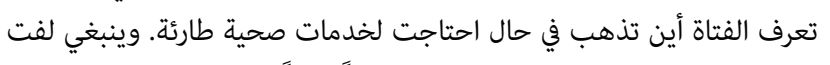

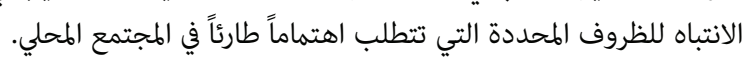

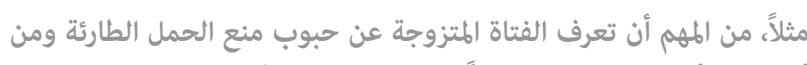

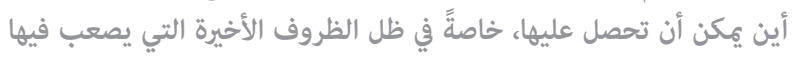

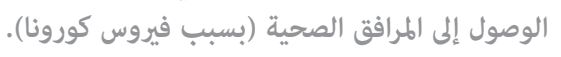

3. يكون لديها مُدَخَرات يمكن الوصول إليها عند حدوث حالة طوارئ شخصية أو عند عجز الأسرة

أظهرت التجربة أن الفتيات بحاجة إلى بعض المدخرات للطوارئ (وبشكل

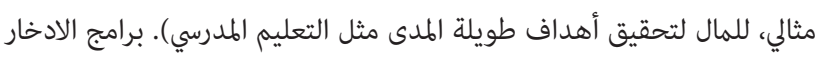

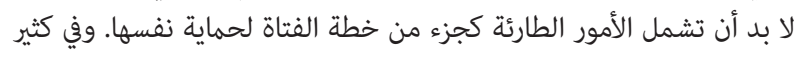

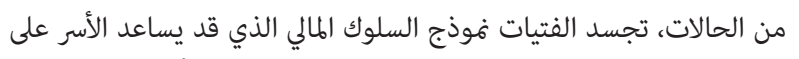

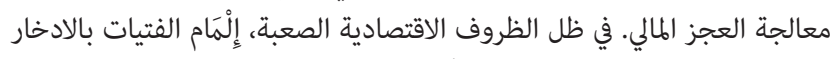
وقكنهن من أن يدخرن أمر مهم جداً.

المرجع: (Smith-Brake and Torres 2012) 
لفتح حساب وذلك لمساعدة الفتيات المهمشات.

المرجع: (Austrian et al. 2012)

13. يكون لديها الوثائق الشخصية اللازمة للوصول إلى الخدمات الصحية

البطاقات الصحية يكن أن تخدم على نطاق واسع كهوية شخصية. بعض البرامج

تسجل كل الفتيات في المركز الصحي المحلي في بداية البرنامج، مما يتيح لهن الهن معرفة مكان الخدمات الصحية ويسهل وصولهن إلى تلك الخدمات

مثلاً، من المهم أن تعرف الفتيات اللاجئات السوريات في لبنان أن الأمم

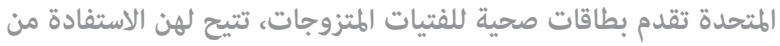

بعض خدمات الحمل والولادة مجانياً.

14. يكون لديها مرشدة أكبر سناً يكن أن تلجأ إليها للحصول على الطشورة عندما تواجه تحديات

وجود أنثى أكبر سناً موثوق بها كمرشدة يساعد الفتيات على التعامل مع تجارب الحياة من خلال شخص يقدم لهن معرفة ويكن أن أن يؤثر على خئى خياراتهن

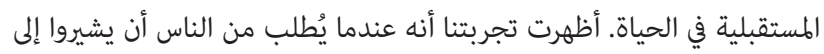
مهاراتهم ”الأساسية“، تكون هذه المهارة في أعلى القائمة دائماً.

\section{5. أن تعرف كيفية لعب الألعاب التقليدية}

أُضيفت هذه المهارة للفتيات اللواتي مل يلعبن أو يقمن بنشاطات رياضية في

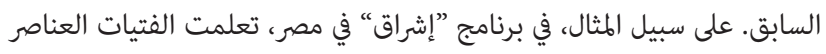

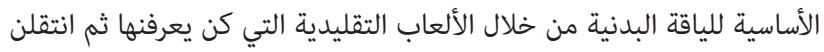

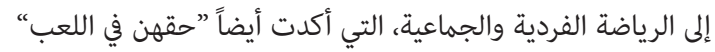

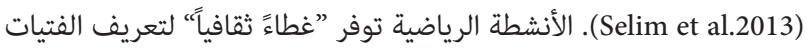

ومجتمعاتهن بفكرة أن اللعب والتفاعل مع الفتيات الأخريات هي مهارات لفافيات لتعريف الفيات مهمة.

المرجع: (Brady and Khan 2002)

16. أن يكون لديها مهارة إنتاجية مدرّة للمال

بناء أساس لسبل عيش الفتاة يبدأ مبكراً. المعارف والههارات المالية تزيد من ثقة

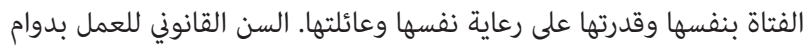

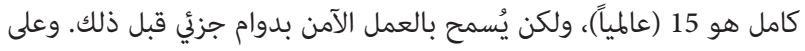

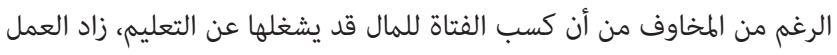

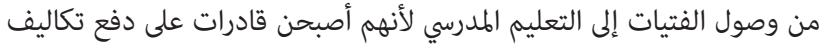

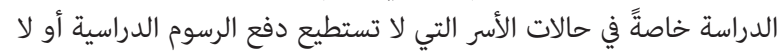
ترغب في ذلك.

المرجع: (Bandiera et al. 2014)
تشير إلى أن الفتيات يَبنين مهاراتهن الاجتماعية والوقائية بأساليب تقلل من

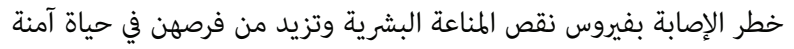

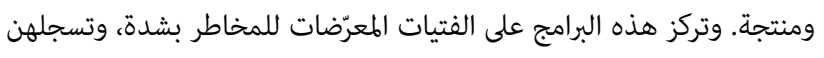

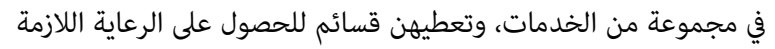

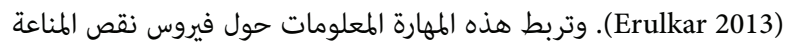
البشرية مع معرفة أهمية الفحص. وتربط هذه الفرة

\section{9. يكون لديها المهارات والثقة لإنشاء ميزانية والمعرفة لمتابعة الدخل والإنفاق}

كل الفتيات يستخدمن الحساب في حياتهن اليومية بما في ذلك اللواتي لا يذهبن

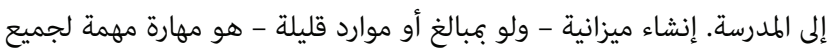

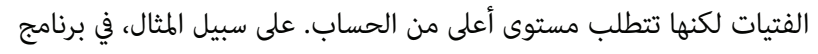

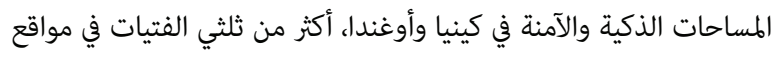

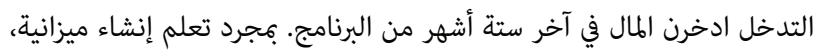

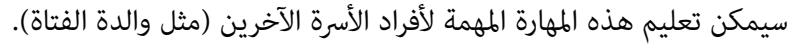

$$
\text { تعلُّم إنشاء ميزانية قلفيات اللاجئات السوريات في لبنان يعملن لسساندة أسرهن ولذلك مفيداً جلك }
$$

10. تعرف كيف تستشير نساء في موقع سلطة إذا كانت تشعر بعدم ارتياح مع ذكر

ينبغي مناقشة هذه المهارة مع الفتيات قبل أن يختبرن حالة طوارئ، بما في ذلك

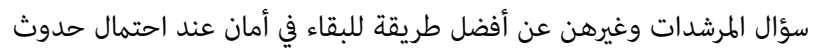

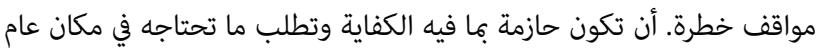
يظهر ثقة في النفس ويقلل من احتمال تعرض الفتاة لموقف غير مريح تُحرم فيه من حقوقها الأساسية التي تستحقها بموجب القانون.

تزيد الظروف التي تعيش فيها الفتيات اللاجئات السوريات في لبنان (العيش العمات

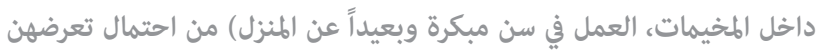
للتحرش، لذلك، الإِكاَمُ بهذه المهارة فين مهم ويساهم في حماية الفتيات. 11. يكون لديها ما لا يقل عن ثلاث صديقات من خارج الأسرة لمعرفة كيفية بناء علاقات مبنية على الثقة مع الأخرين، تحتاج الفتيات إلى شبكة

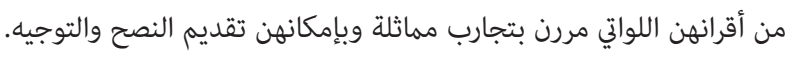

المراجع: (Hallman et al. 2014; Marcus 2014) 12. لديها الوثائق الشخصية اللازمة للوصول إلى الخدمات المالية

يَسمح وجود وثائق/هويات بالحصول على خدمات مالية (بنوك، حسابات

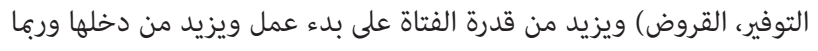

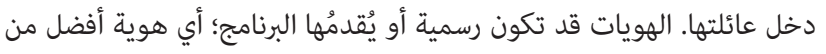

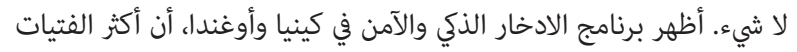

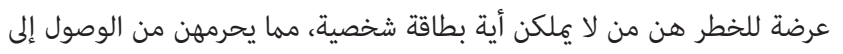

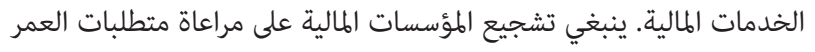


تطلباً لاحتواء المرض ينبغي أن تعرفها الفتيات (والجميع) خلال تفشي الأمراض

المعدية (كالكوليرا والإيبولا مثلا).

20. تعرف متطلبات الوقت اليومية واللوسمية وتعرف كيف تنظم وقتها

في العديد من البلدان النامية، تعمل الفتيات الموظفات لساعات أكثر في اليوم

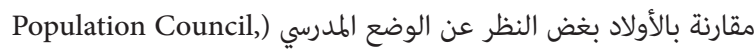

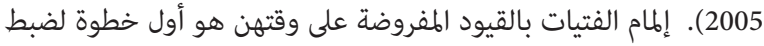
الوقت. الضغوط لإعادة جدولة وقت البرنامج أو التخلي عنه قد لا تظهر في

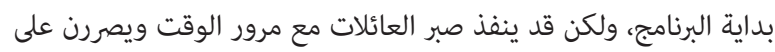

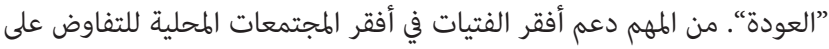

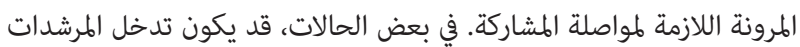
ضرورياً.

المرجع: (Assaad and Bruce 1997)

21. تعرف عن موضوع ختان الإناث (كيف يتم ومتى وكيفية مساعدة شخص مُعَرَضٍ له، وأنه غير قانوني) موضوع خـنان

مازال الختان منتشراً على نطاق واسع مع أنه غير قانوني في العديد من البلدان.

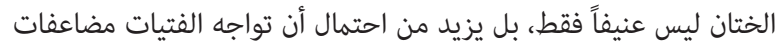

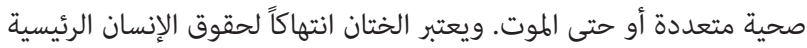

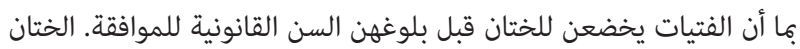

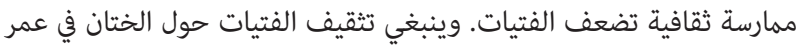
مبكر حيث إنهن يتعرضن له في كثير من الأحيان دون سابق إنذار، وهو يمارَس

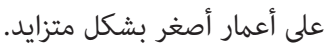

المرجع: (UNICEF Innocenti Research Centre 2008)

22. تستخدم مهارات التفاوض وحل المشاكل بالإضافة إلى معرفة سيناريوهات المخاطر، لتجنب التقاليد المؤذية (مثل الزواج المبكر) الشائعة في مجتمعها

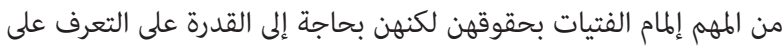

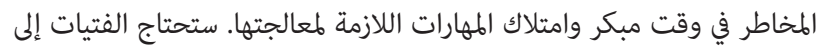
اللجوء إلى شخص من الأسرة أو من خارجها. تدعم مشاركة الاستراتيجيات في الفيات الفيات

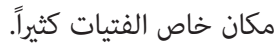

مثلاً، أهالي الفتيات اللاجئات السوريات في لبنان يجبرونهن عادةً على ترك

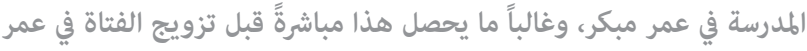

مبكر.

المراجع: (Bruce 2012 \& Mourtada et al 2017)

23. تعرف شخصًا ما يمكن أن تقتزض منه المال عند حدوث حالة طارئة

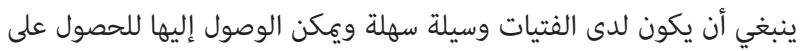

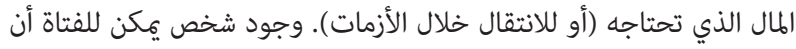

17. تكون قادرة على استخدام مهارات أخذ القرار للتمييز بين خيارات الكسب

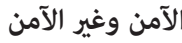

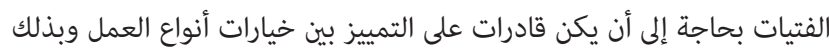

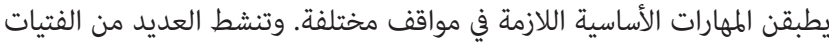

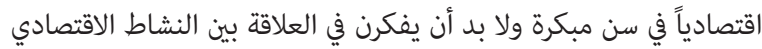

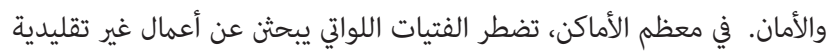

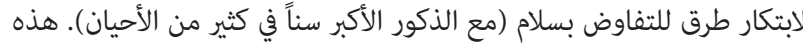

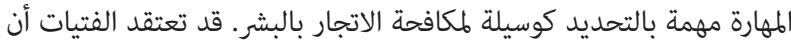

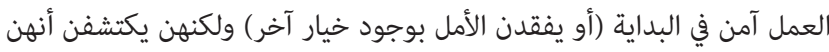

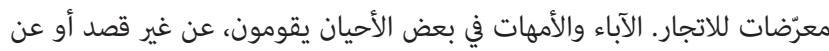

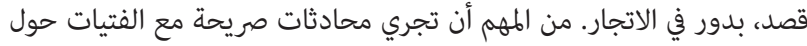

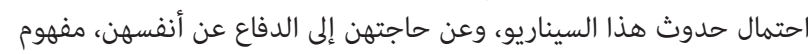
سلامة العمل، وكيفية تجنب المواقف التي قد تؤدي إلى الوقوع في الفخ.

هذه المهارة مهمة للفتيات اللاجئات السوريات في لبنان حيث إن معظمهن يضطررن للعمل بعمر صغير لمساندة أسرهن، ومن الضوريات الضروري للنان حئ أن يعرفن المصادر

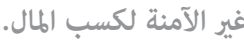

18. أن تعرف الأشياء الأساسية المتعلقة بالدورة الشهرية وكيفية التعامل معها

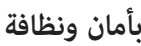

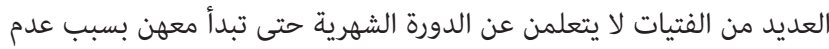

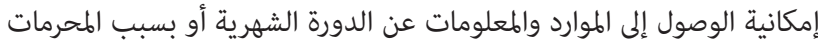

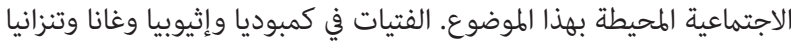

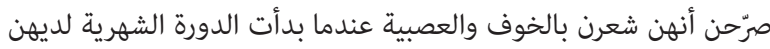

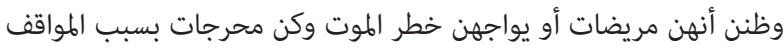

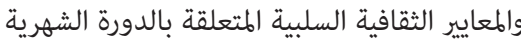
(Sommer et al. 2014).

التحديات التي تواجهها الفتيات تشمل عدم وجود مياه، صرف صحي ملائم،

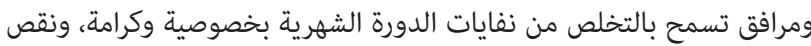

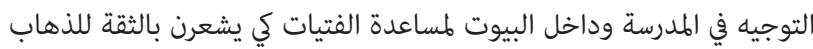

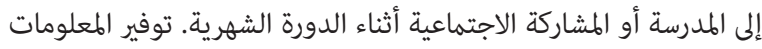

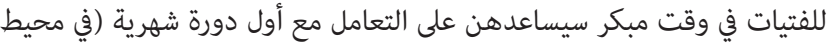

المدرسة، الأسرة، والمجتمع) واكتساب معلومات مهمة حول التعام الصحة الإنجابية.

أظهرت تجارب سابقة في لبنان أن الفتيات اللاجئات السوريات يفتقرن إلى

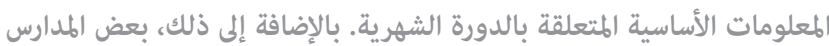

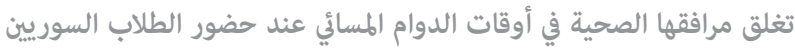
مما يدفع العديد من الفتيات إلى الغياب عن الملدرسة خلال دورتهن الشهاب الشهرية.

19. تعرف متى تغسل اليدين وكيف تغسلهما بشكل صحيح في الحياة اليومية وفي سياق تفشي الأمراض المعدية

غسل اليدين مهم جدا لمنع الإصابة ومهارة يكن للفتيات أن يعلمنها لفتيات أخريات وللأشقاء الأصغر سنا. وقد تكون هناك ممارسات صحية أخرى أكثر المثر 
الفتيات أن توفر قاعدة لتوزيع بعض الأدوية، وقد تشمل موانع الحمل الطارئة.

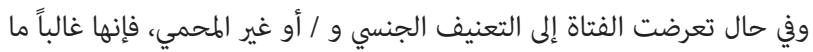

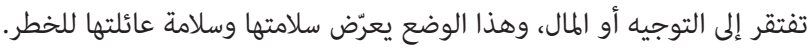

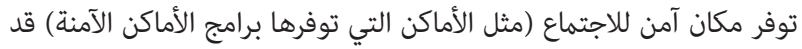

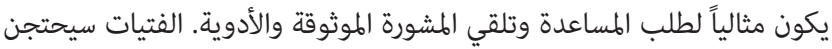

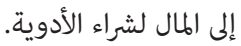

27. يكون عندها مكان آمن لقضاء ليلة خارج المنزل، عند الضرورة

تتعرض العديد من الفتيات إلى الظروف الخطرة بشكل مفاجئ. وبالتالي من المهم أن يكن مستعدات مع خطة أمان تشمل مكاناً آمنا لقضاء ليلة بعيدًا

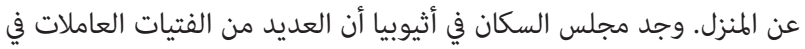

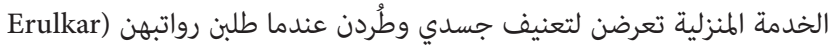

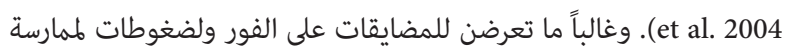
الجنس مقابل المال أو مكان للعيش.

28. تعرف علامات الخطر أثناء الحمل والولادة، وإلى أين تذهب للحصول على

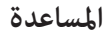

الفتيات لا يواجهن فقط مخاطر الحمل المبكر وغير المرغوب فيه، بل هن عادةً مسؤولات عن مساعدة أخريات في وضع مماثل (مثل أمهاتهن أو صديقاتهن).

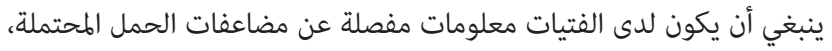

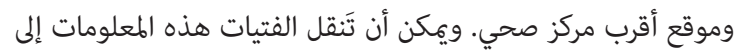

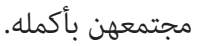

\section{9. تعرف اسم المنطقة التي تعيش فيها}

يتقلص عام الفتيات بشكل كبير وملحوظ خلال فترة البلوغ. يقل إدراك الفتيات

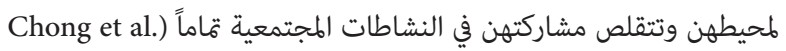

(2006; del Valle 2013; Hallman et al. 2014 المنطقة التي تعيش فيها قد تصل بشكل أسرع إلى حقوقها وتتمكن من المشاركة

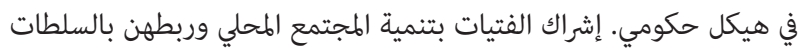
المحلية يساعدهن على المدى الطويل على المطالبة بحقوقهن.

المرجع: (del Valle 2013)

30. يكون لديها القدرة على إخبار والديها أن ما يريدان منها أن تفعله غير قانوني

بناء على ردود الفعل من مجموعات الفتيات، نجد أن هذه المهارة ليست فقط ألفا

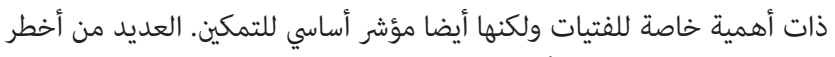

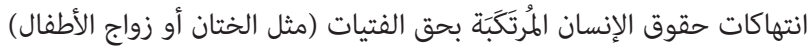

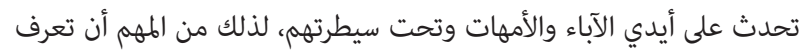

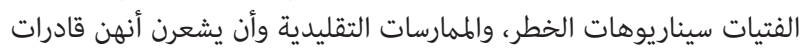
على إبداء رأيهن.

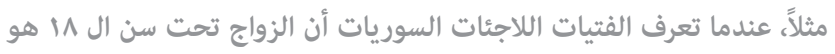

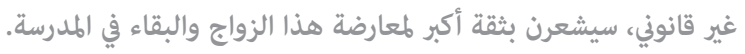

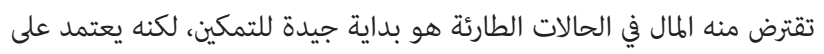

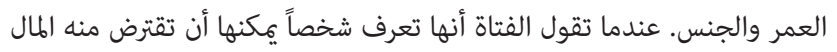

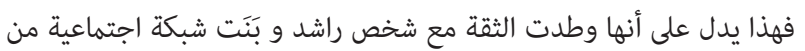

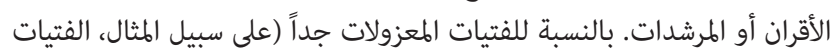

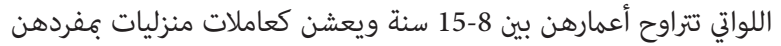

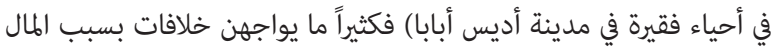

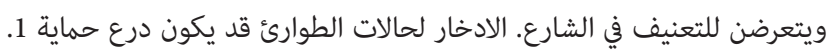
لهؤلاء الفتيات. الدخول في علاقات غير شرعية من أجل الهدايا والهال - أحياناً

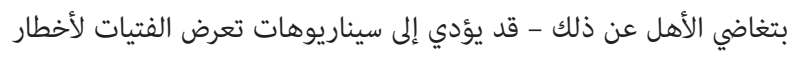
كبيرة.

\section{4. تعرف قواعد السلوك المناسب للمعلمين (بما في ذلك عدم توجيه طلبات خاصة إلى الفتيات أو دعوتهن إلى منازلهم)}

المعلمون وخاصة الذين يمارسون سلطة هائلة قد يعرضون الأطفال وخاصة

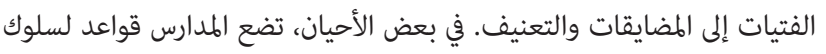

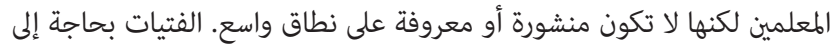

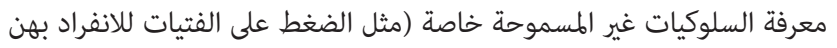

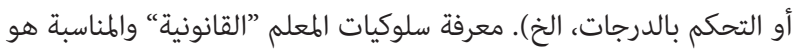
جزء مهم من برنامج السلامة.

المرجع: 2010 EqualityNow n.d.: 10-13; Brady et al.

\section{5. أن تحدد شخصًا يمكن اللجوء إليه عند التعرض إلى تعنيف في المدرسة ومعرفة أين يكن الإبلاغ عن التعنيف}

الفتيات بحاجة إلى استراتيجيات تكنهن من الذهاب إلى المدرسة بأمان. قد

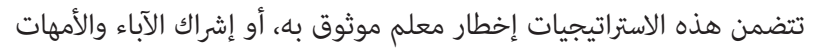

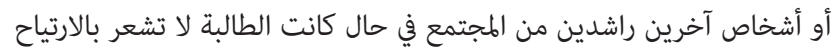

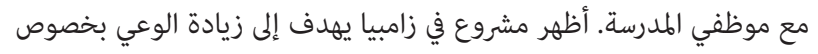
انتشار الاعتداء الجنسي أن الإبلاغ عن الاعتداءات الجنسية زاد بعد زلدئ بداء المشروع.

المرجع: 13-10 المبا

للأسف، الإبلاغ عن التحرش أو الاعتداء الجنسي ليس منتشراً في المجتمعات

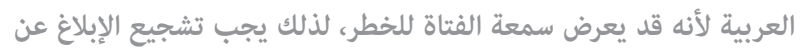

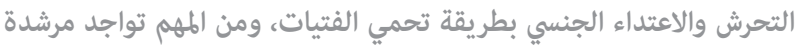

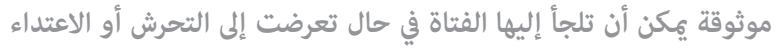

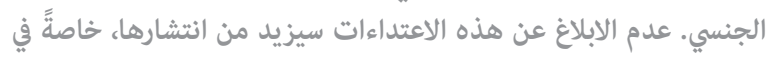

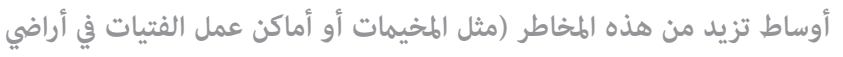

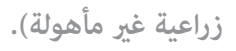

26. تعرف إلى أين تذهب للحصول على الأدوية الأساسية وأن يكون لديها الهال اللازم لشرائها

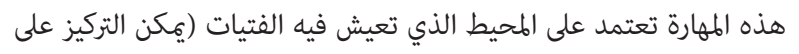

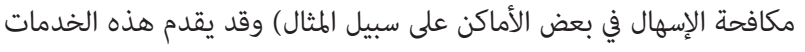

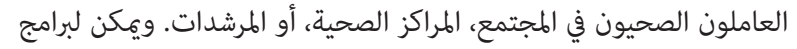


ينبغي أن تعرف الفتاة الحد الأدنى لعدد السنوات الدراسية الذي تفرضه

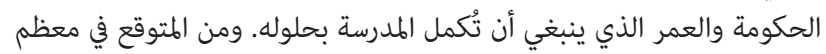

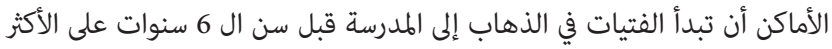

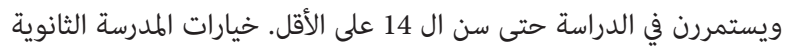

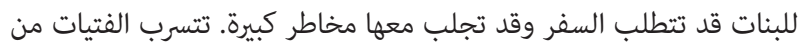

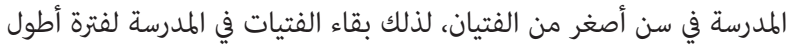

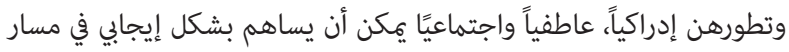
حياتهن.

المرجع: (Population Council and ICRW 2000)

36. يكون لديها مهارات التفاوض وحل المشاكل لتفرض رغبتها في البقاء في المدرسة

الفتيات في ”برنامج +12 ” في راوندا يطورن مهارات للتفاوض على البقاء في المدرسة. وفي حين أنه من الههم أن تفهم الفتيات أهمية التعليم، ولكن الأهم

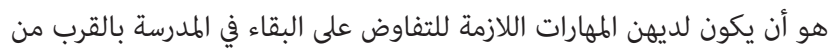

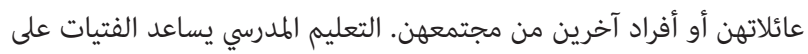

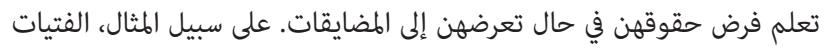

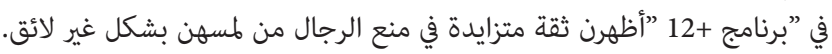

37. تفهم المعلومات البيولوجية المتعلقة بالعلاقة الجنسية والإنجاب

فهم الأساسيات البيولوجية للجنس والإنجاب هو أمر مهم للنمو الصحي للفتاة.

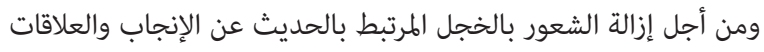

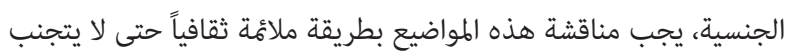
المجتمع المحتوى أو يرفضه بالكامل.

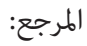

(It's All One Curriculum 2009, popcouncil.org/Itsallone)

38. تكون قادرة على وصف شيء مميز أو خاص عن نفسها وأن تحدّد مهارة يمكن أن تعلّمها للآخرين

هذه المهارة لا تقتصر فقط على زيادة احترام الذات ولكنها تشمل أيضا رؤية

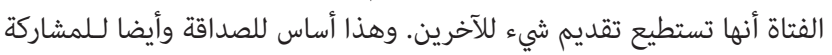
في التغيير الاجتماعي والهياكل الحكومية.

39. أن تعرف كيفية التميز بين النفقات المطلوبة وتلك التي يمكن تأجيلها

هذه قضية أساسية لمحو الأمية المالية - ماذا يحتاج المرء وماذا يريد؟ معرفة

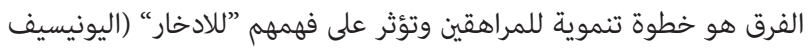

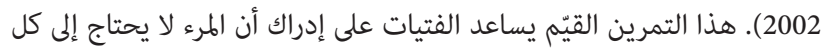

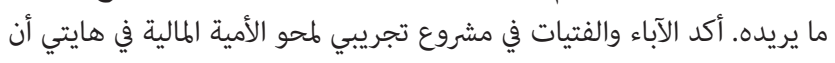

هذه المهارة قيّمة (Smith-Brake and Torres 2012).
غالبا ما تكون المخاطر التي تهدد معيشة الأسرة دورية؛ أي ذات فط. إعلام

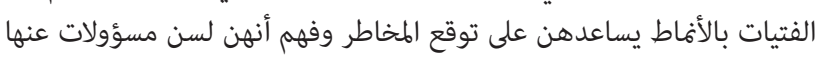

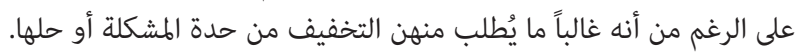

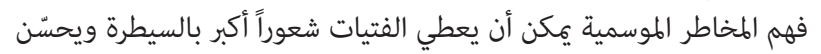

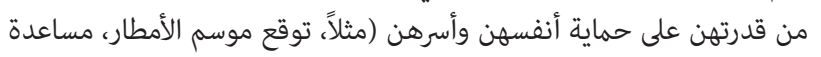

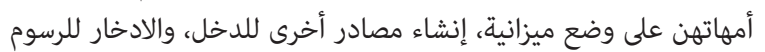

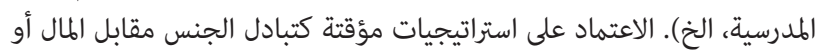

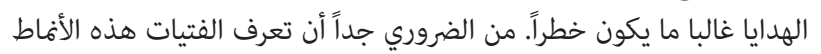
خاصة في حالات الطوارئ (Population Council, 2013)، لأن أفراد الأسرة الضرات

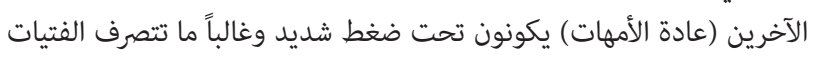
كأوصياء ويخططن لستقبل العائلة.

المرجع: (EDC 2012)

32. يكون لديها أهداف مالية قصيرة الأجل وخطة لتحقيقها

وضع أهداف قصيرة الأجل يساعد الفتيات على اختيار مهام محددة وواقعية

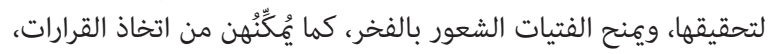

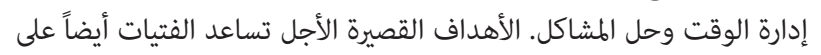

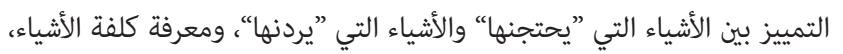

وتحسين مهارات الادخار.

.(Smith-Brake and Torres 2012; Austrian and Muthengi 2013) بالنسبة لفتاة، "أهداف قصيرة الأجل“ قد تعني أسبوعاً فقط ومدخرات قليلة.

33. يكون لديها أهداف مالية طويلة الأجل وخطة لتحقيقها

أهداف الادخار على المدى الطويل قد تكون لفترة قصيرة مثل السنة أو السنتين

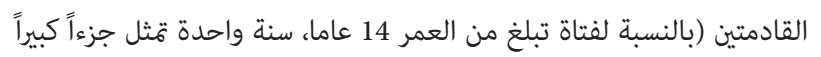

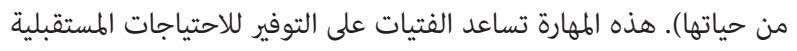

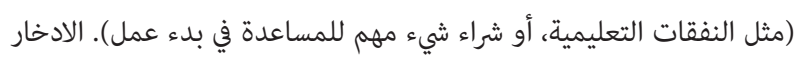

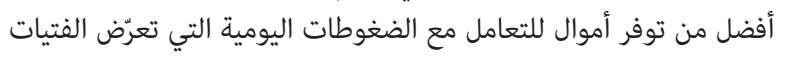

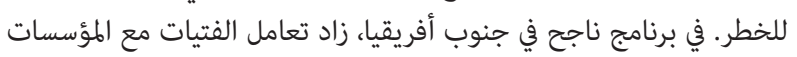

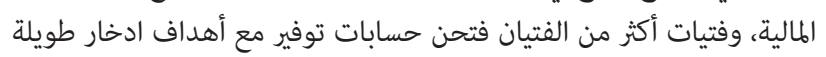

الأجل (Hallman and Roca 2011).

34. تكون قد فكرت بعناية بالههارات التي تحتاجها للقيام بأنشطة مدرة للدخل وممتعة

عادة تُشَجَعُ الفتيات على العمل في مجال معين استنادا إلى الخيارات المحدودة

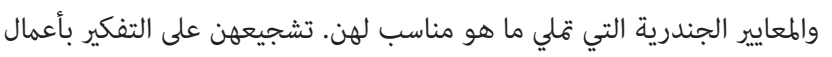
تلهمهن يعزز ثقتهن بأنفسهن وشعورهن بالتمكين ويشجعهن أيضاً أيضاً على اختيار

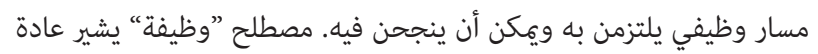

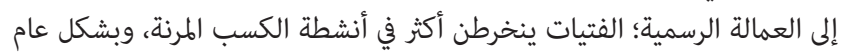
لا يلتزمن بنشاط كسب واحد في وقت واحد.

المرجع: (Population Council and ICRW 2000) 


\author{
أمر مهم كي لا تخسر الفتيات هذه المهارة.
}

45. تعرف السن القانوني للتصويت وأماكن التسجيل والتصويت

قد لا يكون من السهل على الفتيات الحصول على هذه المهارة ولكن يفضل

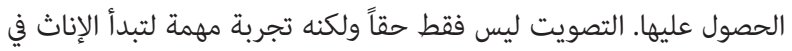

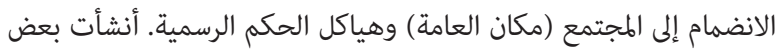

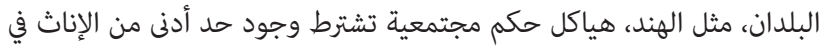

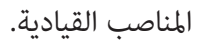

.(Chattopadhyay and Duflo 2004; Agarwal 2008 and 2010) هذا لا يحل المشكلة، ولكن التصويت بنسب عالية وضمان المزيد من المناصب للإناث قد يساعدان في تخصيص موارد للفتيات والنساء.

46. تعرف مهام عمل مجلس الهجتمع المحلي، ومتى يجتمع، وبعض القادة الرسميين

هناك حاجة إلى قنوات رسمية للوصول إلى الهيئات التي تتخذ القرارات

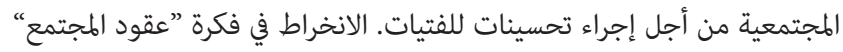

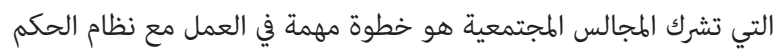

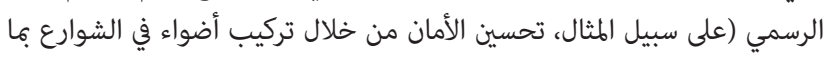

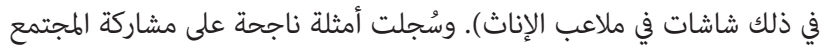

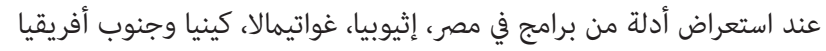

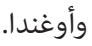

المرجع: (Sewall-Menon and Bruce 2012)

47. تعرف من تسأل / وأين تطلب المساعدة لنفسها أو شخص تعرفه عند

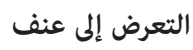

قبل معالجة هذا الموضوع، قد يكون من الضروري أولاً مناقشة معنى العنف.

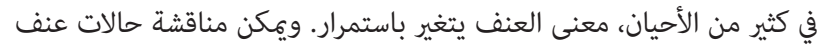

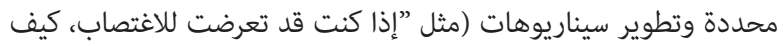

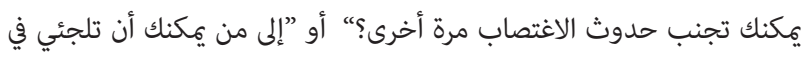

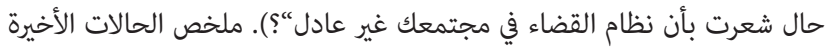

الصادر عن ”صندوق الدفاع القانوني عن المراهقات" (Equality Now n.d)

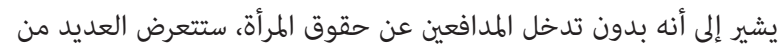

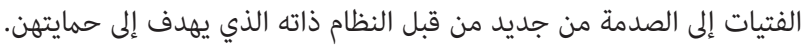

\section{8. تعرف أن العنف لا يقتصر على الغرباء بل يحدث في الأسر غالباً}

ما بين 36-62 في المائة من مجموع الاعتداءات الجنسية المُبَلَغ عنها في جميع أنحاء العالم تُرتكب ضد فتيات يبلغن من العمر 15 سنة أو أقل؛ والعديد منها منها

يحصل داخل الأسر بغض النظر عن المنطقة أو الثقافة (UNICEF 2000).

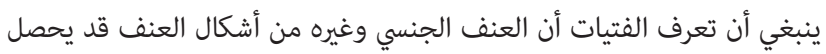

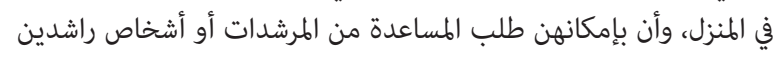
آخرين وموثوقين من خارج العائلة.
40. أن تعرف مزايا وعيوب خيارين (أو ثلاثة) للتوفير

عند النظر في عدة خيارات توفير، اسأل هذه الأسئلة: هل يمكن للفتاة الوصول

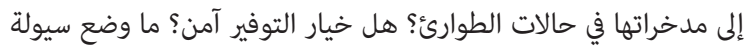

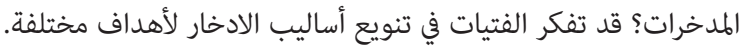

41. تعرف كيف ينتقل فيروس نقص المناعة البشرية، وكيفية الوقاية منه، أين يكن إجراء الفحص، وأن هناك خيارات للعلاج

المعرفة حول فيروس نقص المناعة البشرية لا تُترجَمُ بسهولة إلى حماية ذاتية.

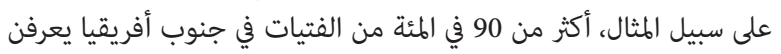

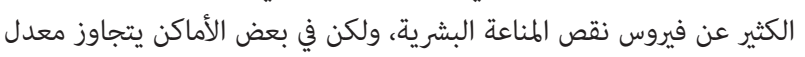

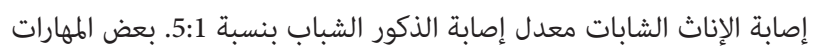

المحددة المتعلقة بالوقاية والفحص ضرورية. الفتابت الفتيات اللواتي شاركن في بناء

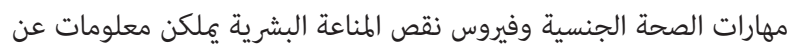

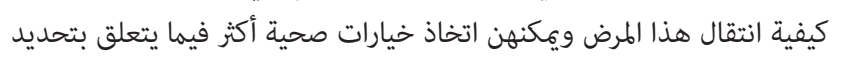
النسل بشكل أكبر. المرجع: (Bruce and Hallman 2008; Bruce et al. 2012)

42. تعرف السن القانوني للعمل والظروف الأساسية المقبولة

السن القانوني للعمل بدوام كامل في جميع أنحاء العالم، وفقا لمنظمة العمل

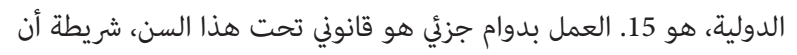

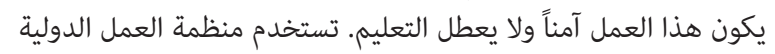

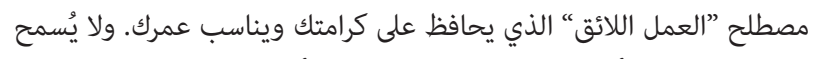
بالعمل الخطر في أي عمر سواءً كان بدوام جزئي أو كامل.

المرجع: (Population Council and ICRW 2000)

43. تعرف أعراض إدمان المخدرات والكحول ومخاطرها وأين يكن أن تطلب المساعدة لنفسها أو لشخص آخر آعران إنرات

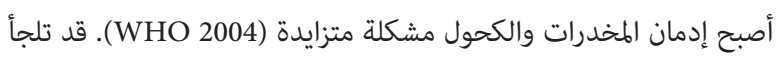

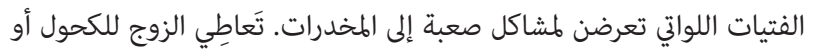

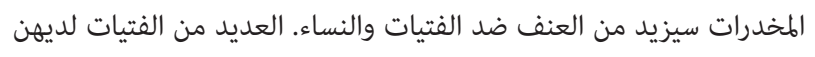

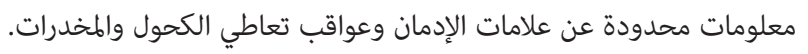
تزويد الفتيات المراهقات بالكعرفة حول تَعاطِي الكحول والطخدرات ومخاطره هو أمر أساسي في تخفيف الاعتماد عليهم.

\section{4. يكون لديها مكان مع ضوء كاف للقراءة لثلاث ساعات في الأسبوع}

القراءة توفر الوقت للتأمل وتُطور مهارات التواصل، بل وربما تساهم في شفاء

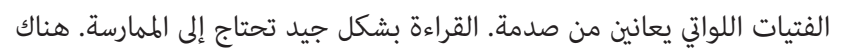

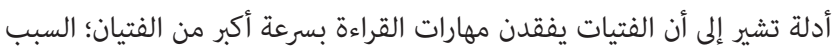

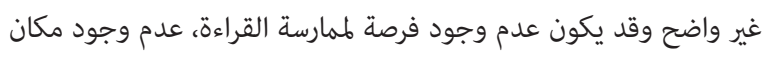

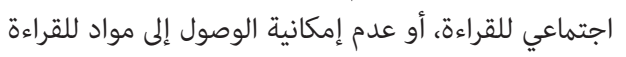

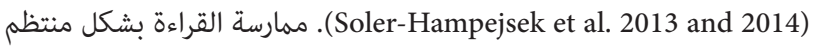


الأصغر سنا، وعموما الفتيات بحاجة إلى طعام أكثر من الفتيان. الفتيات والفتيان

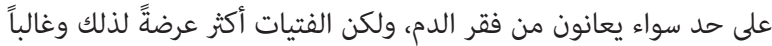

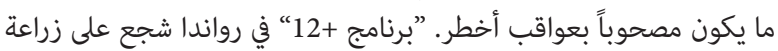
المحاصيل الغنية بالبروتين.

54. تكون قادرة على قراءة جملة بلغتها الأم

هذا هو الاختبار القياسي المستخدم لمعرفة المستوى الأساسي للقراءة والكتابة

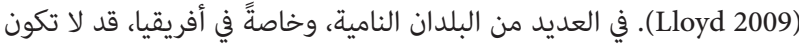
الفتيات قادرات على قراءة جملة بلغتهن الأم بسهولة على الرغم من ذهابهن الرئن إلى المدرسة لسنوات عديدة. ولنقص مهارات القراءة والكتابة لدى الفتيات

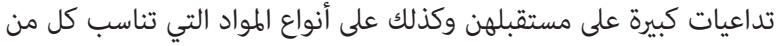
المرشدات (اللواتي قد لا يجدن القراءة) والفتيات.

55. تعرف كيف تصف / تعبر عن مشكلة لشخص في السلطة، مثل مسؤول محلي

ما يحدث للفتاة غالباً يعتمد على سنها وجنسها (وهو ليس ”خطأها“"). الشعور

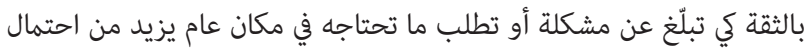

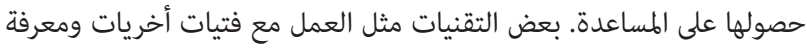
المجتمع المحلي، يمكن أن تساعد في زيادة ثقتها عند مخاطبة شخص الته فئل في السلطة.

56. يكون لديها بطاقة هوية حكومية (الضرورية للتصويت مثلاً)

غالبًا ما تتوفر ”بطاقات الهويّات“ الحكومية ولكن الحصول على بطاقة قد

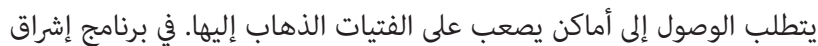

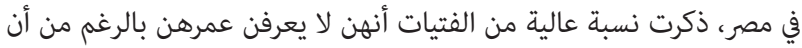

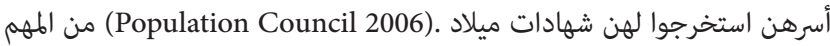

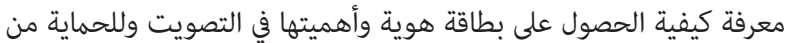
الزواج تحت السن القانوني.

57. تعرف البرامج الحكومية و / أو المستحقات التي قد تكون هي / أو أهلها مؤهلين للحصول عليها وكيفية الحصول عليها

بناء مهارات حماية للفتيات لا يقتصر فقط على اكتساب مهارات و إتقانها ولكنه

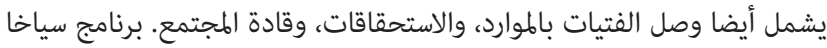

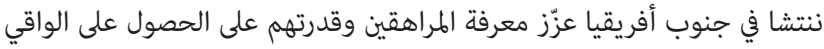

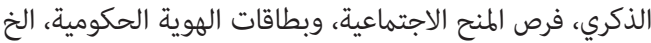

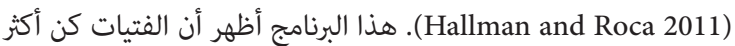

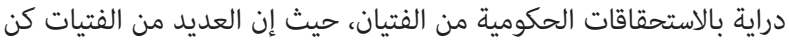

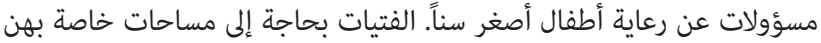
في المجتمع وإلى معرفة كيفية الوصول إلى البرامج المتوفرة.

58. تعلم أن زواج الأطفال يرتبط بضعف الصحة، الفقر، والطلاق (وأن الطلاق ينطوي على مخاطر اجتماعية واقتصادية)

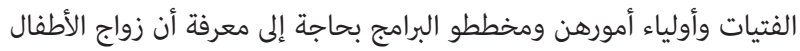

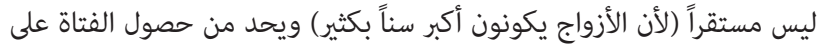

من الضروري أيضاً تدريب المرشدات المحليات على كيفية مساعدة فناة

تعرضت إلى العنف.

المرجع: (CDC 2009; UNICEF 2014)

49. تعرف المبادئ الأساسية للدفاع عن النفس وطرق جذب المساعدة

من المهم معرفة الههارات الأساسية والفعالة للدفاع عن النفس (وفي أي مكان). أحياناً تساعد الصافرات ولكن يكنن تجاهلها ببساطة كما يحصل في هايتي مثلاً،

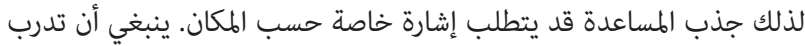

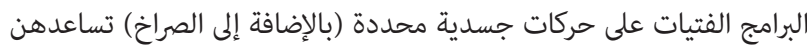

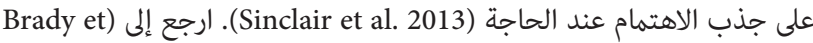
al. 2010 الذي يشمل المزيد من المعلومات عن هذا الموضوع.

المرجع: (Brady et al. 2010)

50. تعرف ما هو سوء المعاملة والفرق بين ”اللمسة الجيدة“" "اللمسة

السيئة

كثيراً ما تتعرض الفتيات للاعتداء الجنسي والعنف اللذين قد يبدآن بشكل عفوي

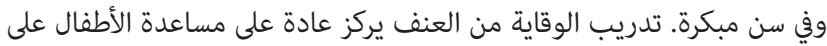

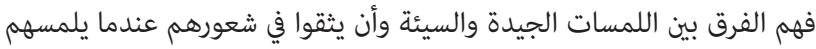

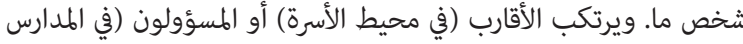

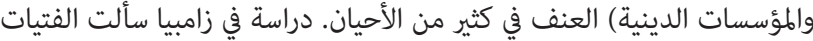

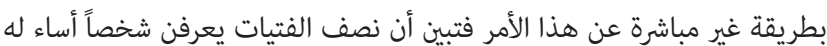

أحد أفراد الأسرة (Brady et al. 2010).

من المرجح أن هذا يحصل أيضاً في أوساط اللاجئين السوريين في لبنان، خاصةً أن إن إندان العديد من العائلات اضطرت إلى العيش في بيت أو أو خيمة واحدة.

51. تعرف عندما تشعر بالجوع ويكون عندها الشجاعة لإخبار شخص تثق به

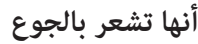

العديد من الفتيات يقبلن الجوع كحالة طبيعية ومن ثم يحاولن سد جوعهن بطرق غير رسمية ومحفوفة بالخخاطر، مثل تبادل الجنس مقابل الطعام أو المال.

52. تعرف كيف تحصل على الأطعمة الرئيسية التي تحتاجها

في "برنامج +12 ” في رواندا، تعلمت الفتيات عن الأطعمة الرئيسية التي يحتجن الفناء

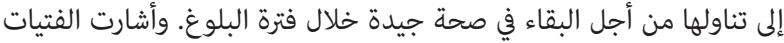

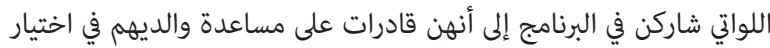
الأطعمة التي تساعدهم على البقاء في صحة جيدة.

53. تَعرفَ أن المراهقات يحتجن إلى طعام أكثر من الفتيات الأصغر سناً (على الى

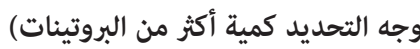

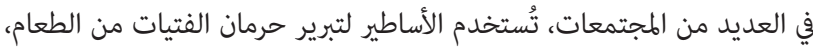

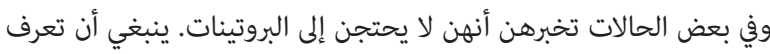

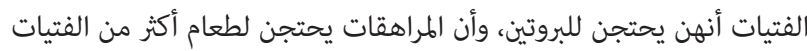


المجتمع، ولكن يجب مناقشة هذه المسألة مع الفتيات.

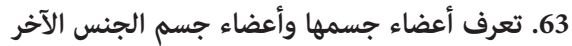

من الواضح أن هذه معرفة أساسية ولكنها أيضا وسيلة لتخفيف الحرج أحرج في حال

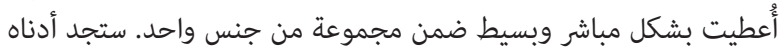
مرجعاً قيماً من مجلس السكان عن التثقيف الجنسي.

المرجع: (It's All One Curriculum 2009, popcouncil.org/itsallone)

\section{4. تعرف الوقت في اليوم / الأسبوع الذي قد تواجه فيه المزيد من المخاطر في

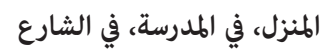

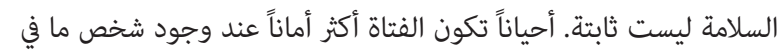

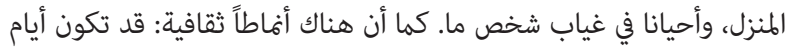

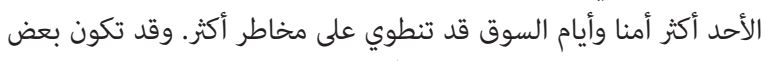

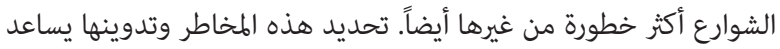

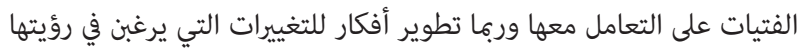

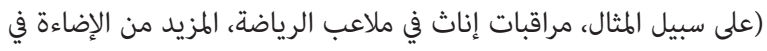

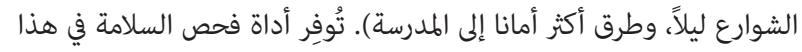

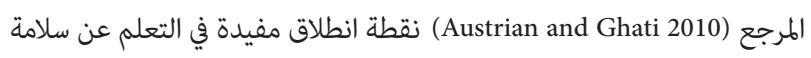

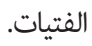

المراجع: (Austrian and Ghati 2010; Hallman et al. 2014)

\section{5. تعرف الأماكن الآمنة والأوقات التي يمكن أن تخرج فيها لوحدها (أو أخوات عندما يكون الخروج في مجموعات أكثر أماناً)}

يتعلق الوقت الآمن لخروج الفتاة بمفردها بالمكان والزمان ويختلف حسب اليوم

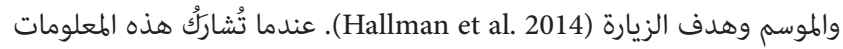

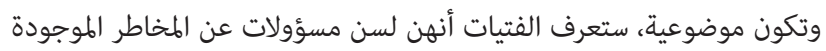

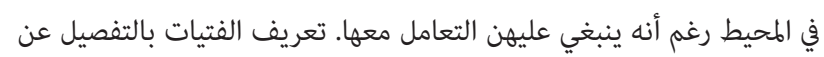

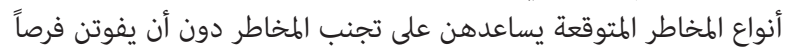

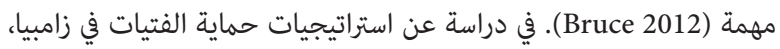

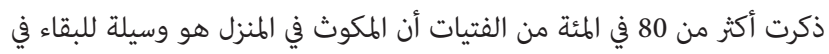

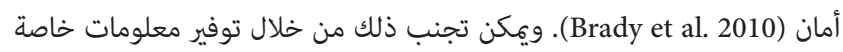

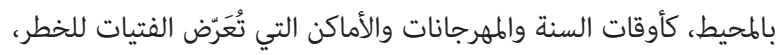

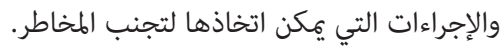

66. تعرف وتدلي بحقها في تحديد عدد الأطفال الذين تريديهم وتوقيت الولادات

هذه المهارة هي عبارة عن قوانين في معظم البلدان. تنظيم الأسرة قانوني ومعظم

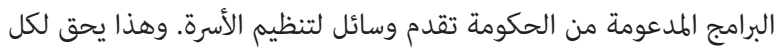

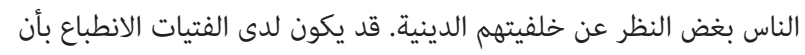

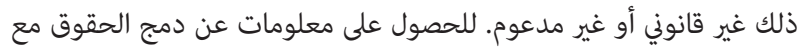
التربية الجنسية، يرجى الاطلاع على المرجع أدناه.

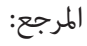

التعليم أو مصدر رزق لائق. دراسة ”راكاي“ لخطر الإصابة بفيروس نقص المناعة

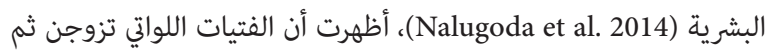

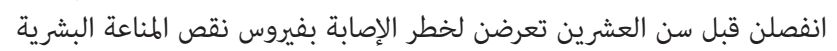

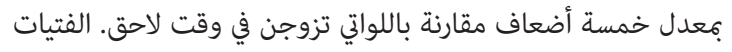

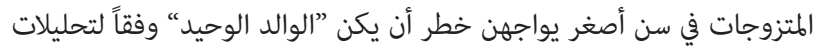
أجريت في 15 بلداً (Clark and Hamplovà 2013).

59. تكون قادرة أن تتخذ قرارات ”زواج“، آمنة وصحية وبحزم واحترام

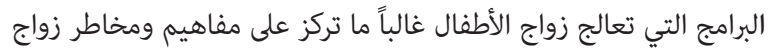

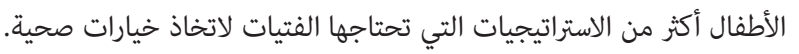

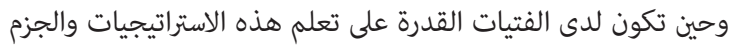

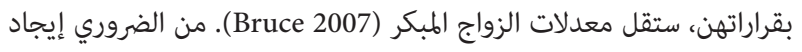

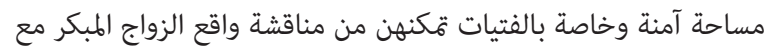
بعضهن البعض ومع المرشدات الأكبر سنا.

المرجع: (Bruce 2007)

\section{0. تعرف موقع مركز المجتمع المحلي والأنشطة التي يقدمها وكيفية المشاركة}

من المهم أن تعرف الفتيات أن هناك مراكز مجتمع يحق لهن الاستفادة منها وتجري فيها أنشطة قد تفيدهن وتُتخَذ قرارات قد تؤَثر عليهن.

\section{1. تعرف موقع وساعات عمل الأماكن الهخصصة للفتيات}

من المهم أن تعرف الفتيات فوائد الأماكن المخصصة لهن، في حال كانت متوفرة،

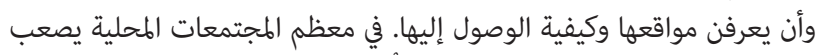

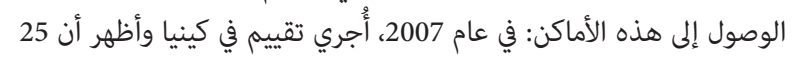

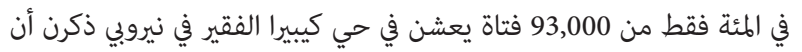

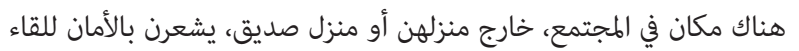

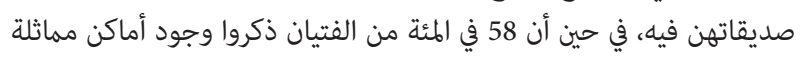

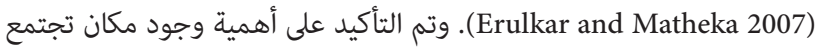

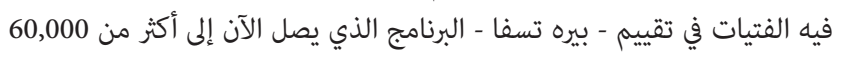

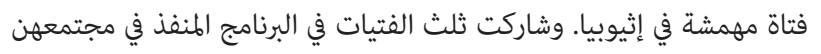

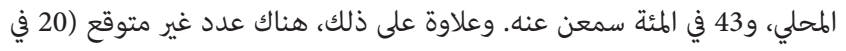

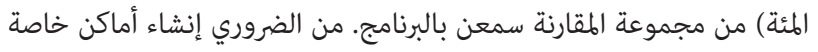

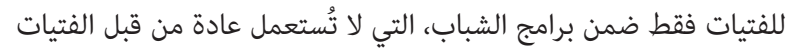

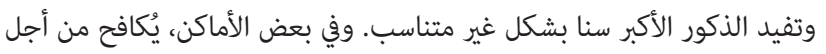

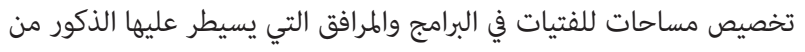
خلال خلق أماكن محددة أو أماكن خاصة بالفتيات لفات لساعات محدودة.

المراجع: (Erulkar et al. 2011; Erulkar et al. 2013)

62. أن تعرف ما يمكن / لا يمكن قوله لشخص كان ضحية لجريمة عنيفة

أول رد على شخص كان ضحية لجريمة عنيفة مهم: قد يزيد أو يخفف وصمة ألمارة

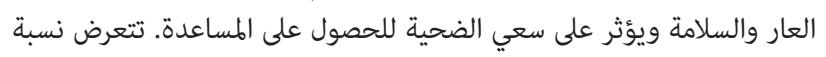

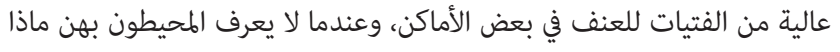

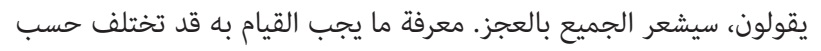




\section{1. تعلم أن لها نفس حقوق شقيقها}

يجب أن تعلم الفتيات أن لهن نفس حقوق الإنسان مثل أشقائهن. هذا مهم

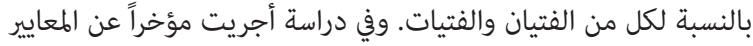

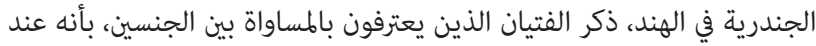

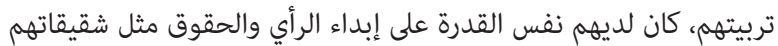

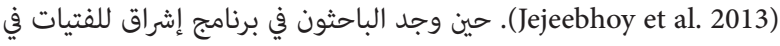

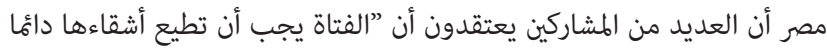

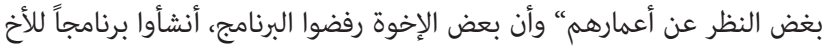

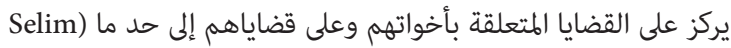

(et al. 2013

72. لديها خطة للحفاظ على مهاراتها (القراءة والحساب) خلال العطل

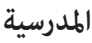

أظهرت الأبحاث الأخيرة أن الفتيات قد يحققن نفس مستويات القراءة لدى ألى إك

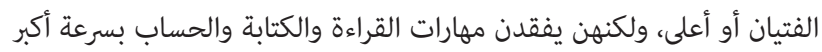

من الفتيان عندما يتركن المدرسة (Soler-Hampejsek et al., 2013 and 2014).

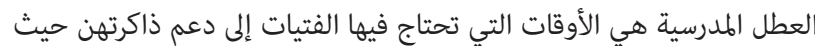

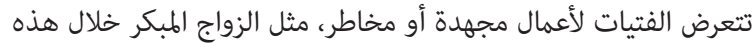

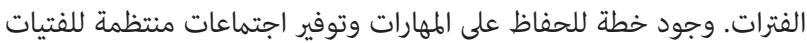

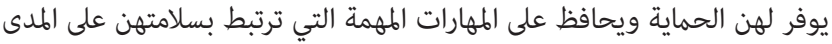

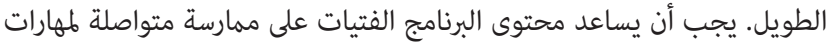

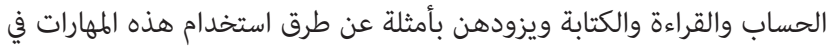

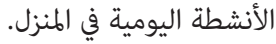

73. تعرف كيفية تحديد مصدر مياه آمن (أو أن تحصل على مساعدة لفحص

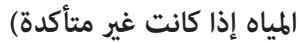

غالباً ما تُكلف الفتيات بالعثور على الماء ونقله (سواء للشرب أو لأغراض أخرى).

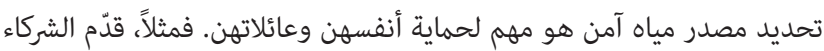

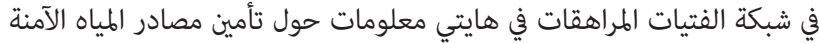

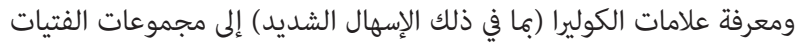

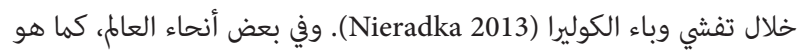
الحال في جنوب آسيا، هناك أيضا مخاوف بشأن الزرنيخ في الماء. الإلمام بتلوث

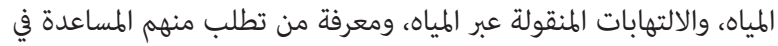
فحص المياه هي أمور مهمة للفتيات.

74. تعرف كيفية الإصابة بالملاريا وكيفية تثبيت شبكة السرير وصيانتها

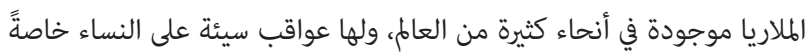

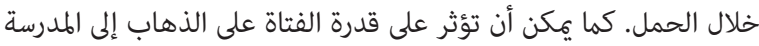

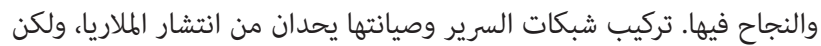

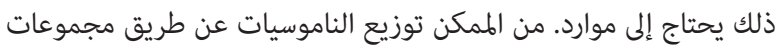

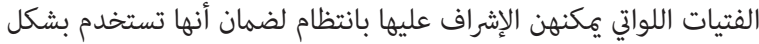

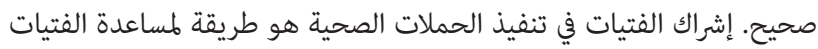
على حماية مجتمعاتهن وتعزيز قوتهن الشخصية وتحسين صورتهن الفين داخل تلك الك

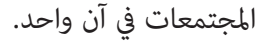

(It's All One Curriculum 2009, popcouncil.org/itsallone) 67. تعرف عن الاتجار بالجنس وأشكال أخرى من الجنس القسري (على سبيل المثال الإقناع والابتزاز)، وأين تحصل على المساعدة

تعريف الاتجار واسع ويشمل أي خداع أو استعمال للعنف للسيطرة على فتاة

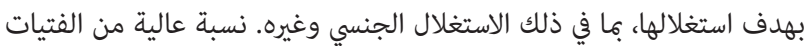

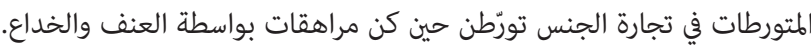

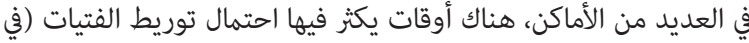

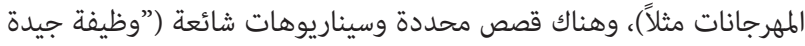

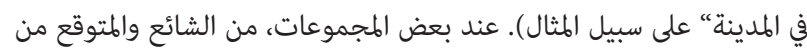

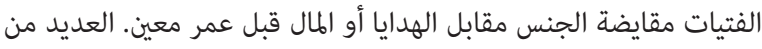

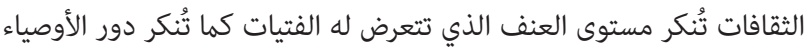

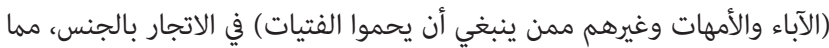

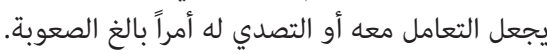

\section{8. تعرف رقم خط المساعدة (الخط الساخن) للتبليغ عن أي عنف أو

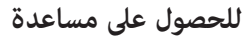

شكلت خطوط المساعدة الموجودة في المناطق التي يوجد فيها خدمة منتظمة إلفاء

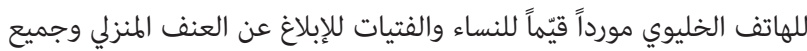

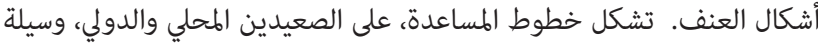

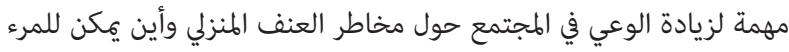

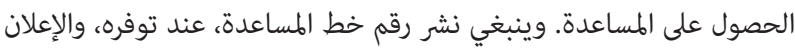

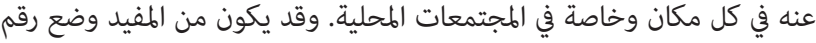

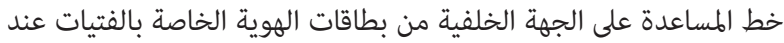
إعدادها. هذه المهارة ترتبط بالمحيط حيث إن بعض الأماكن قد لا يتوفر فيها

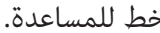

\section{9. تعرف أنه يجب عدم قبول أي طعام أو شراب من الغرباء}

يعتبر تقديم الطعام للفتيات الجائعات في بعض الأماكن شكلاً من أشكال

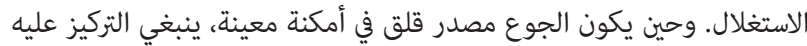

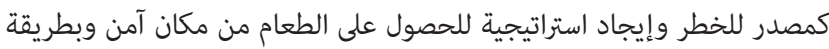

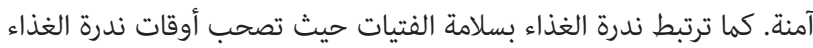

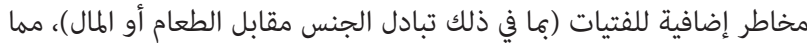

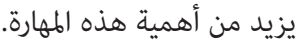

70. تعلم أن تعدد الزوجات هو غير قانوني

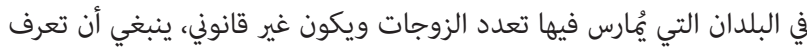

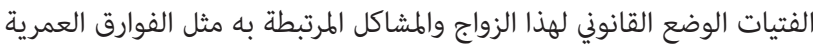

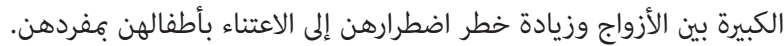

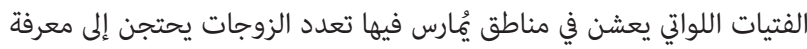

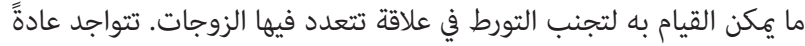

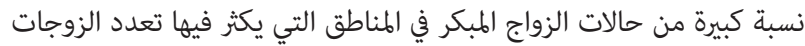

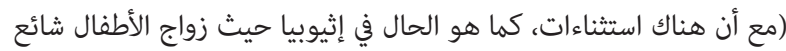

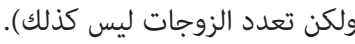


للحصول على فرص جديدة (Bruce 2012). في دراسة في زامبيا، قالت 86 في

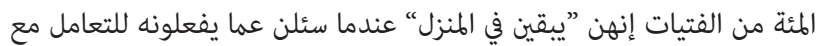

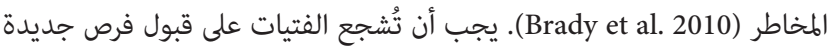

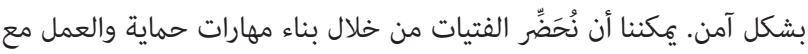

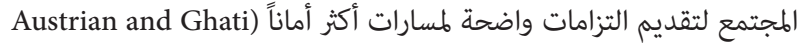

(2010; del Valle 2013

\section{0. تعرف أسماء أشخاص مدربين في المجتمع يمكن الاعتماد عليهم لحماية} الفتيات (الأوصياء)

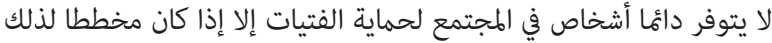

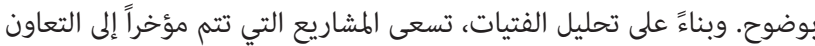

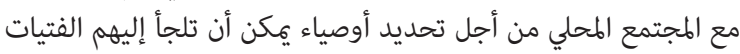
ويمكنهم متابعة التقدم الذي يحققه المجتمع المحلي بالنسبة إلى أهداف معينة.

.(Sewall-Menon and Bruce 2012)

\section{1. تدافع عن نفسها أو صديقاتها إذا تعرضن للإهانة}

الفتاة الحازمة التي تستطيع التعبير عن حقوقها واحتياجاتها الشرعية هي قادرة

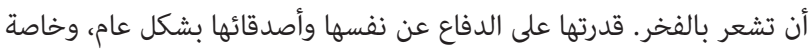

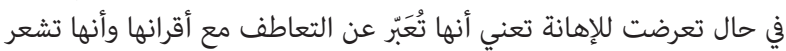
بقيمتها. هذا ضروري لإنشاء صداقات والهحافظة عليها.

82. تعرف كيفية الوقاية من الأمراض المنقولة جنسياً، بما في ذلك فيروس نقص المص

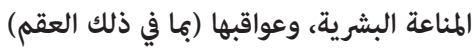

الإلطام بفيروس نقص المناعة البشرية (الإيدز) هو مقياس فوذجي لإنجازات

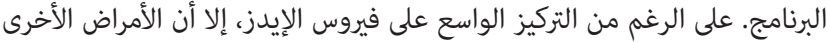

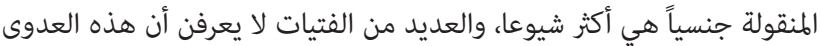

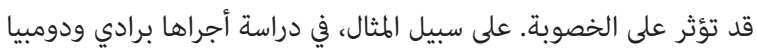

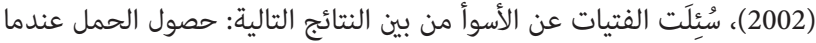

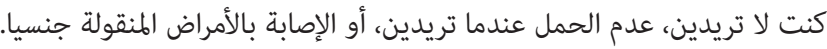

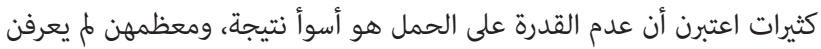

$$
\text { أن هناك علاقة بين الأمراض المنقولة جنسياً والخصوبة. }
$$

المراجع: (It's All One Curriculum 2009, popcouncil.org/itsallone)

\section{3. تعرف مكانًا للحصول على واقي ذكري ووسائل منع الحمل وأين يمكن الحصول على المشورة والتعليمات}

أفضل الخدمات للفتيات هي تلك المتعددة الأبعاد. فعلى سبيل المثال، القسائم

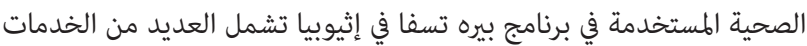

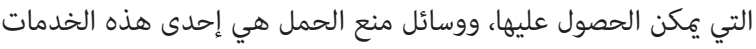

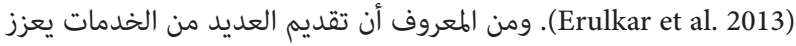

قبولها.

المراجع: (It's All One Curriculum 2009, popcouncil.org/itsallone)
المراجع: (Catino 2012; K4Health 2014)

75. تشعر أنها ذكية مثل الآخرين

هذا مقياس مثير للاهتمام لأنه غالباً ما يميز ليس فقط بين الفتيان والفتيات في

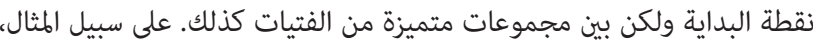

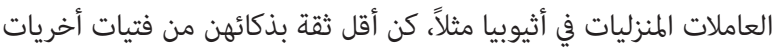

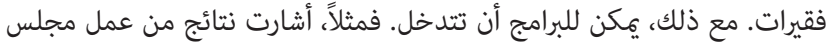

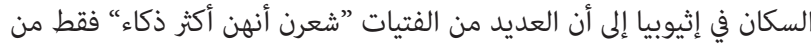
خلال المشاركة في البرنامج، مع أن البرنامج لم يهدف إلى إلى هذه النيات النتيجة. (Erulkar and Muthengi 2008; Erulkar et al. 2010) وجود فتيات أخريات زاد من شعور الفتيات بقيمتهن وقدراتهن.

76. تيكون لديها بطاقة قموينية

من المهم أن يكون لدى الفتاة بطاقة قوين (قسيمة لازمة للحصول على مواد

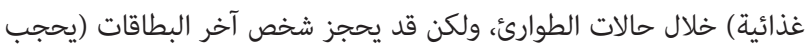

إمكانية الوصول إلى الحصص الغذائية). كيفية الاحتفاظ ببطاقات الفتيات التموينية بأمان أمر يستحق البحث فيه.

77. تعرف الأوقات والطرق الآمنة إلى مصادر المياه وأماكن جمع الحطب، بـا في ذلك خلال حالات الطوارئ ت تلطئ

ضمان الأمان (خاصة خلال حالات الطوارئ) هو شيء لا تستطيع السلطات

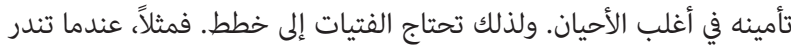

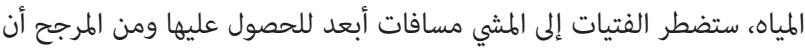

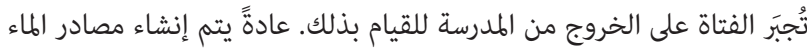
في الأسبوع الأول من الأزمة من دون الأخذ بعين الاعتبار مكان إقامة الفدر الفتيات.

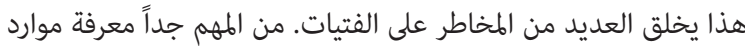

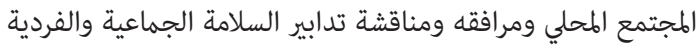
.(Women's Refugee Commission 2012)

78. تعرف شخصاً يمكنه المساعدة في الترجمة (إلى اللغات الرسمية الرئيسية)

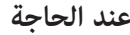

قد يتسبب تحدث لغة عرقية فقط وعدم الإمام بلغة الأغلبية / اللغة الرسمية

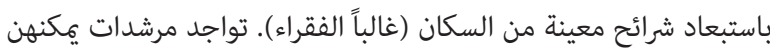

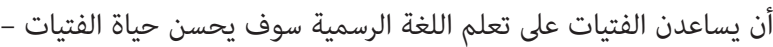

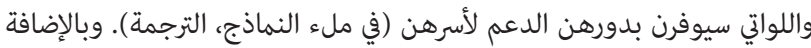

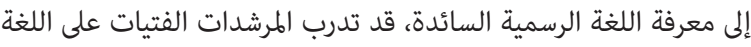

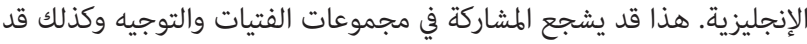

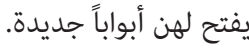

79. يكون لديها خطة أمان وتكون قادرة على تسمية ثلاثة مخاطر تواجهها

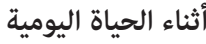

الفتيات بحاجة إلى فهم أنهن غالبا ما سيحتجن إلى التعامل مع بعض المخاطر 
معرفة الموارد في مجتمعاتهن (Kenworthy, Hallman, and Diers 2008).

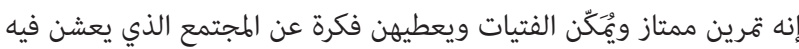
ويعطيهن دوراً فيه.

\section{9. تعرف كيف تكتب رسالة بسيطة لتطلب شيئاً}

كتابة رسالة هو تمرين جيد ليس لتطوير المهارات الإدراكية فقط ولكنه أيضاً

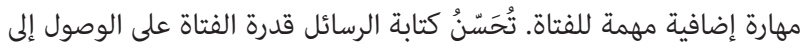
الموارد والتحكم فيها، وهي مدرجة على قائمة المهارات الأساسية لمنظمة العمل

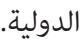

\section{0. تعرف كيف تكتب رسائل نصية وترسلها وتستخدم وسائل التواصل

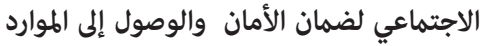

تعتمد فائدة وسائل التواصل الاجتماعي لدى الفتاة على عمرها وتوفر

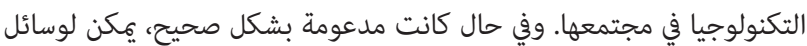

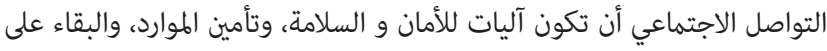

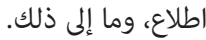

\section{1. عرف كيف تلأ النماذج}

وصول الفتيات غالباً ما يكون محدوداً على الرغم من أنهن عادةً يعرفن القراءة

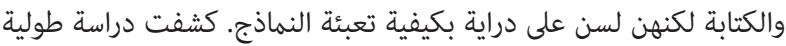
أجريت في ملاوي عن اختلاف مستوى المعرفة بين الفتيان والفتيات الذين لديه ديهيه

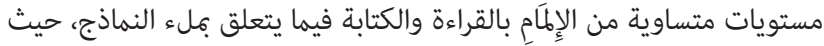

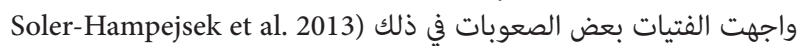

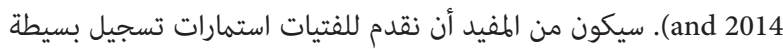
(للخدمات الصحية، وأمور أخرى) ونتأكد من فهمهن لها وكيفية ملئها بشكل

صحيح.

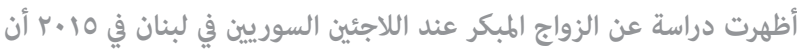

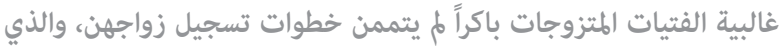

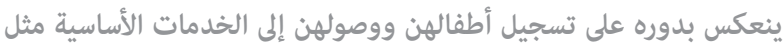

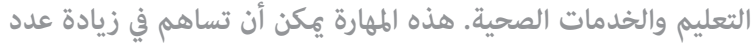
الفتيات اللواتي يعرفن الخطوات والنماذج المطلوبة لتسجيل زواجهن.

92. تعرف الرياضيات الأساسية (الكسور، الأرقام العشرية، والنسب المئوية) وكيفية حساب التكاليف البسيطة

الحساب هو مهارة أساسية في كسب العيش. وجدت أبحاث أُجريت في ملاوي

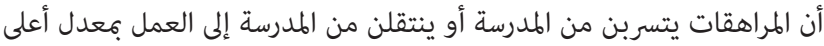

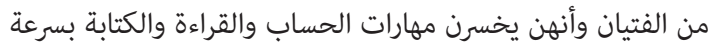

(Soler-Hampejsek et al. 2013 and 2014; Population Council 2014) الفتيات بحاجة إلى الاستعداد ليكن مسؤولات مالياً عن أنفسهن وعلى الأرجح

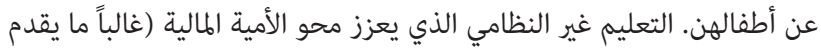

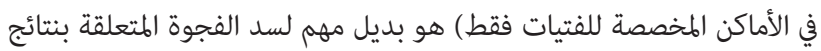

مهارات الحساب بين الجنسين. (Lloyd 2009).
84. تعرف العاملين الصحيين المحليين والأنشطة الصحية المحلية

لا تقتصر فائدة هذه المعرفة على رفاهية الفتاة فقط بل تربط الفتيات بشبكات

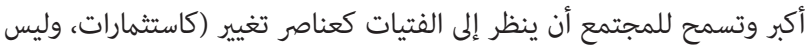

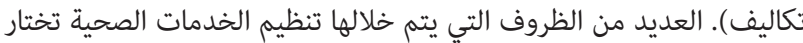

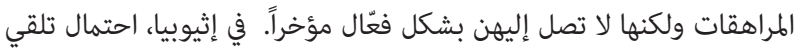

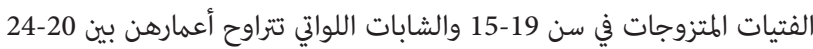
زيارة من عامل صحي مجتمعي هي حوالي نصف احتمال حصول امرأة فوق بن

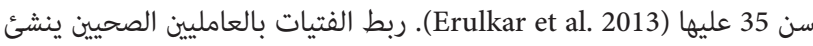
علاقة مهمة لأنه يساعد العاملين الصحيين على ”رؤية، فتيات مل يروهم مسبقاً.

\section{5. تكون قادرة على التواصل جيدًا مع مجموعة من الأقران وكبار السن}

بناء الثقة ومهارات التواصل لدى الفتاة أمر مهم. مهارات التحدث أمام جمهور

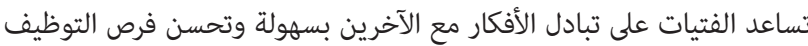

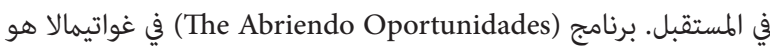
مثال على دعم مرشدات وفتيات أثناء تقديهن نتائج ”خطة الاكتشاف الآمن“ بالإضافة إلى تعريف احتياجاتهن (de valle, 2003) .

86. الحصول على موافقة الوالدين للعمل والوصول إلى فرص آمنة

إتاحة الوقت والهكان للفتيات للاستفادة من الفرص هو أمر ضروري لساعدة

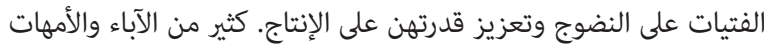

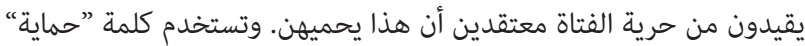

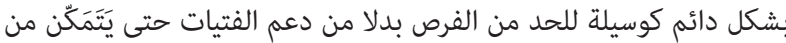

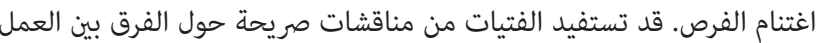

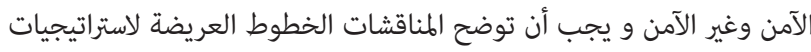

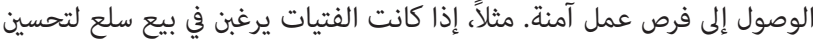
سبل معيشتهن، فسيحتجن إلى خطة جيدة إضافة إلى دعم وفهم والديهن. المراجع: (del Valle 2013; Girl Hub 2014)

87. ممارسة مهارات القراءة والحساب بانتظام مع وسائل الإعلام المتاحة وفي مواقف الحياة اليومية

القراءة النقدية لوسائل الإعلام المطبوعة وممارسة مهارات الحساب والقراءة

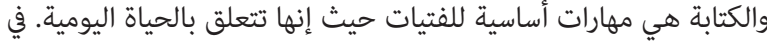

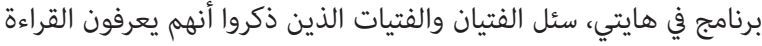

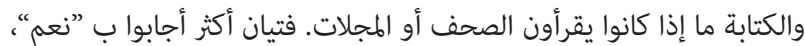

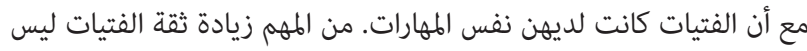
فقط من خلال تشجيعهن على قراءة الأخبار ولكن من خلال نقد كيفية تمثيل الفتيات والمجموعات الأخرى في وسائل الإعلام.

المرجع: (2015 fracturedatlas.org).

88. تعرف كيف تقرأ الرسومات التخطيطية أو الخرائط

هذه مهارة إدراكية وبصرية رئيسية. في العديد من برامج الفتيات، الفتيات لا

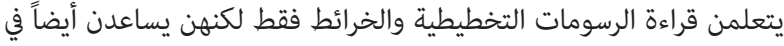


98. تشعر أنه بإمكانها أن تقول ”لا" لأصدقائها إذا كانوا يضغطون عليها لكي تقوم بعمل لا تراه صائباً

امراهقة هي وقت صعب بالنسبة للفتيات. هن يتأثرن كثيرا بأقرانهن وغالبا

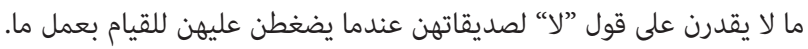

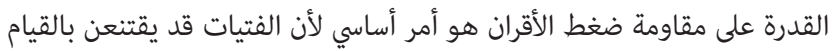
بأشياء تضر بهن (مثل تعاطي المخدرات، والسرقة).

المرجع: (It's All One Curriculum 2009, popcouncil.org/itsallone) 99. تعرف أعراض الأمراض المعدية، وكيف تعزل فرداً ومن أين تطلب

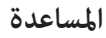

خلال أزمة الإيبولا، كانت هناك حاجة إلى نشر معلومات دقيقة بين عدد كبير

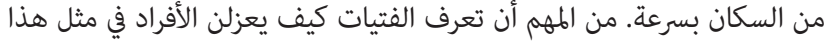

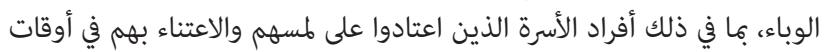

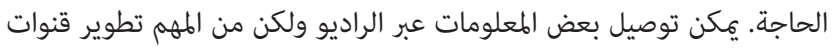

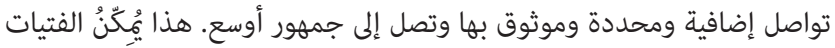

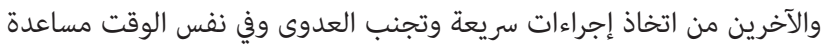
شخص مصاب في الحصول على الرعاية التي يحتاجها.

المرجع: (Bah 2014)

100. تعرف أن العديد من الأمراض تنتقل عبر العلاقات الجنسية (من أشخاص

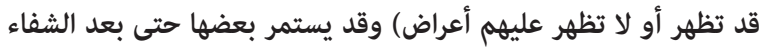

مع تطور أزمة الإيبولا، أوقفت حكومة سيراليون البرامج غير المرتبطة مباشرة

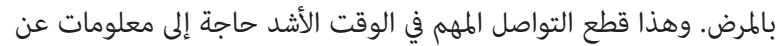

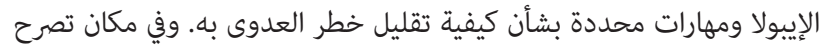

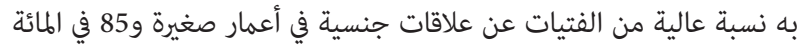

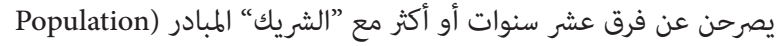

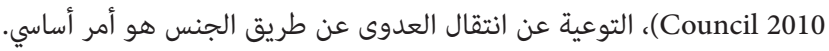

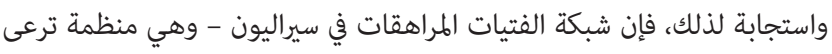
نوادي الفتيات المجتمعية - أعطت الأولوية لإعلام الفتيات بهذه الماندات المخاطر بشكل

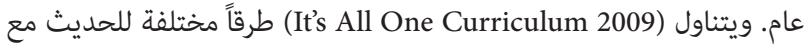
شريك جنسي محتمل حول الصحة والسلامة.

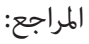

/It's All One Curriculum 2009, popcouncil.org)

(itsallone; Bah and Bruce 2014
93. تستمع إلى الراديو وتشاهد التلفزيون للحصول على المعلومات

غالبا ما تكون إمكانية وصول الفتيات إلى الإذاعة والتلفزيون محدودة، خاصة إذا

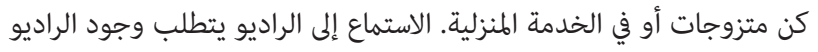

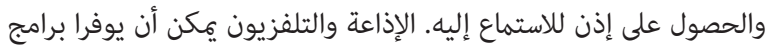

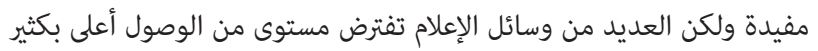

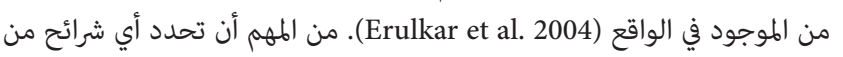
الفتيات لا يصلن إلى الراديو والتلفزيون ولا يمكنهن الاستفادة منهما.

94. تكون قادرة على التعبير عن المشاعر وتخبر صديقة أو شخصاً راشداً موثوقاً عن مشكلة في المدرسة أو في المنزل

لا يمكن للفتيات معالجة المشاكل الخطيرة وحدهن دون مساعدة شخص راشد

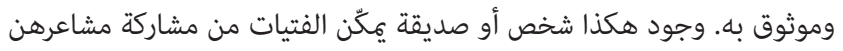

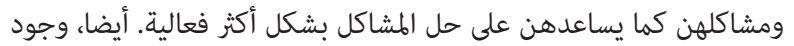

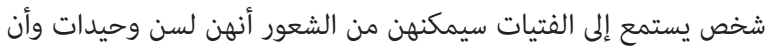
مشاعرهن مهمة.

الموارد: (Jones and Bouffard 2012; casel.org)

95. تستخدم مهارات التواصل والاستماع الفعّال (الاستماع مع التعاطف والصبر؛ التحدث بحزم وليس بعنف مهار لتواصن

مهارات التواصل هي مهمة لبناء علاقات صحية والتعلم من الآخرين والعمل

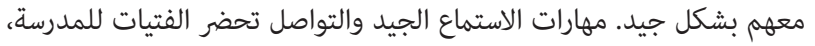

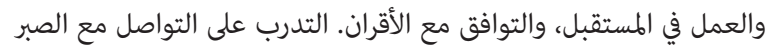
والتعاطف والتأكيد يساعدهن على التواصل والتوافن معاحترام.

الموارد: (Jones and Bouffard 2012; casel.org)

96. لديها القدرة على تخفيف حدة خلاف نشأ بين الأصدقاء وزملاء الدراسة الفتيات بحاجة إلى مهارات في حل الخلافات حتى يتمكن من تخفيف حدة

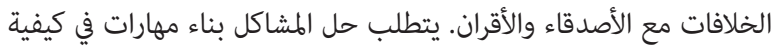

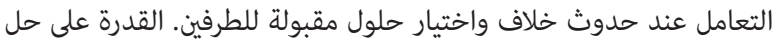

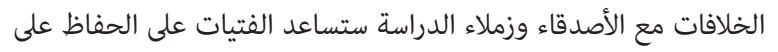

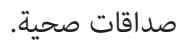
الموارد: (Jones and Bouffard 2012; casel.org) 97. تتحكم بالغضب عندما تكون في مواقف صعبة

إدارة الغضب والقدرة على ضبط العواطف هما أمران مهمان لخلق الصحة

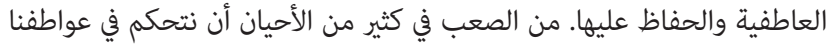

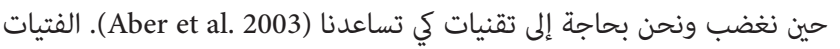
سيستفدن من القدرة على ضبط عواطفهن والغضب في المواقف الصعبة، لأن الحفاظ على الهدوء سيساعدهن على التحكم بالتوتر بشكل أسهل. 
المراجع

Aber, J. Lawrence, Joshua L. Brown, and Stephanie M. Jones. 2003. "Developmental trajectories toward violence in middle childhood: Course, demographic differences, and response to school-based intervention," Developmental Psychology 39(2): 324-348.

Agarwal, Bina. 2008. "Overcoming participatory exclusions," in The State of Access, Success and Failure of Democracies in Creating Equal Opportunities (eds.), Gowher and de Long,Washington, DC: Brookings Institution Press.

-_-. 2010. "Does women's proportional strength affect their participation? Governing local forests in South Asia,"World Development 38: 101.

Assaad,Marie and Judith Bruce. 1997. "Empowering the next generation: Girls of theMaqattam garbage settlement," SEEDS. Population Council. [Also, in Arabic.]

Austrian, Karen and Dennitah Ghati. 2010. "Girlcentered program design: A toolkit to strengthen and expand adolescent girls programs." Section 4. Population Council.

Austrian, Karen and Eunice Muthengi. 2013. "Safe and Smart Savings products for vulnerable adolescent girls in Kenya and Uganda: Evaluation report." Nairobi: Population Council.

-_-. 2014. "Can economic assets increase girls' risk of sexual harassment? Evaluation results from a social, health, and economic asset-building intervention for vulnerable adolescent girls in Uganda," Children and Youth Services Review 47(2): 168-175.

Austrian, Karen, Eunice Muthengi, AngelaWambugu, Dennitah Ghati, and Elizabeth Kariuki. 2012. "Safe and Smart Savings for Vulnerable Girls in Kenya and Uganda: The evolving model, lessons learned, and recommendations." New York: Population Council. www.popcouncil.org/uploads/pdfs/2012PGY_ SmartSavingsProgramBrief.pdf.

Bah, Chernor. 2014. "It's young girls and women on the frontlines of the Ebola crisis." Huffington Post. 31 October. www.huffingtonpost.com/chernor-bah/

Bah, Chernor and Judith Bruce. 2014. "Ebola and women: Chernor Bah on the impact on girls in Sierra Leone." Ebola Deeply blog. 6 November. www.eboladeeply.org/ articles/2017/11/6494/ebola-women-chernor-bah-impactgirls-sierra-leone/\#!
Bandiera, Oriana, Niklas Buehren, et al. 2014. “Womens' empowerment in action: Evidence from a randomized control trial in Africa," Gender Impact Evaluation Database.Washington, DC:World Bank.

Brady,Martha and Seydou Doumbia. 2002. "Projet promotion de la jeunesse et des sports, Mali.” UNFPA final report.

Brady,Martha and Arjmand Banu Khan. 2002. "Letting girls play: TheMathare Youth Sports Association's football program for girls." UNFPA final report.

Brady, Martha, Joseph Simbaya, Allison Stone, and Maya Vaughan-Smith. 2010. "Understanding adolescent girls' protection strategies against HIV: An exploratory study in urban Lusaka." New York: Population Council.

Bruce, Judith. 2007. "Child marriage in the context of the HIV epidemic: Transitions to adulthood." Brief No. 11. Population Council. www.popcouncil.org/uploads/pdfs/ TABriefs/PGY_Brief11_ChildMarriageHIV.pdf.

---. 2012. "Violence against adolescent girls: A fundamental challenge to meaningful equality." Girls First! Series. New York: Population Council. www. popcouncil.org/uploads/pdfs/2012PGY_GirlsFirst_ Violence.pdf.

Bruce, Judith, and Kelly Hallman. 2008. "Reaching the girls left behind,” Gender and Development 16(2): 227-245.

Bruce, Judith, Miriam Temin, and Kelly Hallman. 2012. "Evidence-Based Approaches to Protecting Adolescent Girls at Risk of HIV." AIDSTAR-One Spotlight on Gender.Washington, DC: USAID.

Catino, Jennifer. 2012. "The health of vulnerable adolescent girls: A strategic return on investment." www. popcouncil.org/uploads/pdfs/2012PGY_GirlsFirst_ Health.pdf.

CDC. 2009. Together for Girls:We Can End Sexual Violence. www.cdc.gov/violenceprevention/pdf/ togetherforgirlsbklt-a.pdf.

Chattopadhyay, Raghabendra and Esther Duflo. 2004. "Women as policy makers: Evidence from a randomized policy experiment in India," Econometrica 72(5): 14091443.

Chong, Erica, Kelly Hallman,Martha Brady. 2006. "Investing when it counts: Generating the evidence base for policies and programmes for very young adolescents-Guide and tool kit." 
Clark, Shelley and Dana Hamplovà. 2013. "Single motherhood and child mortality in sub-Saharan Africa: A life course perspective," Demography 50(5): 1521-1549.

del Valle, Angel. 2013. "Addressing violence against adolescent girls through 'safescaping' (participatory community mapping).” UNFPA webinar series for Adolescent Girls Initiative.

-_-. 2014. "Community contracts: Accountable efforts to support girls and sustain safe spaces." Addis Ababa: Learning Circle workshop. EDC. 2012. "Equip 3 Lessons learned: Experiences in livelihoods, literacy and leadership in youth programs in 26 countries, 20032012." EQUIP3 and USAID.

Engebretsen, Sarah. 2012a. "Using data to see and select the most vulnerable girls." Girls First! Series. New York: Population Council.

Engebretsen, Sarah. 2012b. "Case study: Building a program based on identified assets.” New York: Population Council. http://designingforscale.popcouncil. org/?page_id=37

Equality Now. n.d. Learning from Cases of Girls' Rights. www.equalitynow.org/sites/default/files/Learning_ From_Cases_of_Girls_Rights.pdf.

Erulkar, Annabel, A. Ferede,W. Ambelu, et al. 2010. "Ethiopia young adult survey: A study in seven regions." Addis Ababa: Population Council and UNFPA. www. popcouncil.org/ uploads/pdfs/2010PGY_EthiopiaYASurvey.pdf.

Erulkar, Annabel, A. Ferede,W. Girma, andW. Ambelu. 2013. "Evaluation of "Biruh Tesfa" (Bright Future) program for vulnerable girls in Ethiopia." Vulnerable Children and Youth

Studies 8(2): 182-192.

Erulkar, Annabel, Herma Gebru, and Gebeyehu Mekonnen. 2011. "Biruh Tesfa program provides domestic workers, orphans and migrants in urban Ethiopia with social support, HIV education and skills." Addis Ababa: Population Council. www.popcouncil.org/ uploads/pdfs/2011PGY_BiruhTesfaBrief.pdf.

Erulkar, Annabel and JamesMatheka. 2007. Adolescents in the Kibera Slums of Nairobi, Kenya. Nairobi: Population Council.

Erulkar, A.S., T. Mekbib, N. Simie, and T. Gulema. 2004. "Adolescent life in low income and slum areas of Addis Ababa." Ethiopia: Population Council. www.popcouncil. org/uploads/pdfs/AdolescentLife.pdf.
Erulkar, Annabel S. and Eunice Muthengi. 2008. "Evaluation of Berhane Hewan: A pilot program to promote education and delay marriage in rural Ethiopia." Addis Ababa, Ethiopia: Population Council. fracturedatlas.org. 2015. "Center for the Arts, Port Au Prince: Working to empower adolescent girls in Haiti in the arts and create income-generating activities." www. fracturedatlas.org/site/fiscal/profile?id=6142

Girl Hub. 2014. "Girl safety toolkit: A resource for practitioners."www.girleffect.org/resources/2014/05/girlsafety-toolkit/

Haberland, Nicole and Deborah Rogow (eds.). 2011. It's All One Curriculum: Guidelines and Activities for a Unified Approach to Sexuality, Gender, HIV, and Human Rights Education. New

York: Population Council.

Hallman, Kelly. 2011. "Social exclusion: The gendering of adolescent HIV risks in KwaZulu-Natal, South Africa," in J. Klot and V. Nguyen (eds.), The FourthWave: Violence, Gender, Culture \& HIV in the 21st Century. Social Science Research Council and UNESCO, pp. 53-80.

Hallman, Kelly, Nora Kenworthy, Judith Diers, et al. 2014. "The contracting world of girls at puberty: Violence and gender-divergent access to the public sphere among adolescents in South Africa." Global Public Health.

Hallman, Kelly and Eva Roca. 2011. "Siyakha Nentsha: Building economic, health, and social capabilities among highly vulnerable adolescents in KwaZulu-Natal, South Africa." Transitions to Adulthood Brief No 4. New York: Population Council.

Hallman, Kelly, Eva Roca, Kasthuri Govender, et al. 2012. "Siyakha Nentsha: A randomized experiment to enhance the health, social and financial capabilities of girls and boys in KwaZulu-Natal, South Africa." Paper presented at the Annual Meeting of the Population Association of America, San Francisco, CA.

Jejeebhoy, S.J., K.G. Santhya, and S. Sabarwal. 2013. "Gender-based violence: A qualitative exploration of norms, experiences and positive deviance." New Delhi: Population Council.

Jones, S.M. and S.M. Bouffard. 2012. "Social and emotional learning in schools: From programs to strategies." Social Policy Report 26(4): 1-33. K4Health. 2014. "Care and repair of mosquito nets toolkit." https://www.k4health.org/toolkits/care-repairLLIN. 
Kenworthy, Nora, Kelly Hallman, and Judith Diers. 2008. "Identifying sources of adolescent exclusion due to violence: Participatory mapping in South Africa." Transitions to Adulthood Brief No. 30. New York: Population Council.

Loyd, Cynthia B. 2009. New Lessons: The Power of Educating Adolescent Girls. New York: Population Council.

--_. 2012. "Priorities for adolescent girls' education," Girls First! Series. New York: Population Council.

Marcus, Rachel. 2014. "Changing discriminatory norms affecting adolescent girls through communications activities: Insights for policy and practice from an evidence review." Overseas Development Institute.

Mourtada, R., Schlecht, J., \& DeJong, J. (2017). A qualitative study exploring child marriage practices among Syrian conflict-affected populations in Lebanon. Conflict and health, 11(1), 53-65.

Nalugoda, Fred, D. Guwatudde, J.B. Bwaninka, et al. 2014. "Marriage and the risk of incident HIV infection in Rakai, Uganda." JAIDS 65(1): 91-98.

Nieradka, Jessica. 2013. "Safe spaces for adolescent girls in Haiti." Haiti Adolescent Girls Network. www.haitigirls network.org/news-section/blog/safe-spaces-adolescentgirls-haiti.

Population Council. 2005. "Building assets for safe, productive lives: A report on a workshop on adolescent girls' livelihoods," 7-8 April 2004. http://www.popcouncil. org/uploads/pdfs/BuildingAssets_Oct05.pdf.

-_-. 2006. "Providing new opportunities to adolescent girls in socially conservative settings: The Ishraq program in rural Upper Egypt." New York.

. 2010. "The adolescent experience: Using data to reach the most vulnerable young people: Sierra Leone 2008." New York.

--_. 2013. "Girls in emergencies. Report from a workshop.” 7-9 December. New York.

---. 2014. "Malawi Schooling and Adolescent Study."www.popcouncil.org/research/malawi-schoolingand adolescent-study.

Population Council and ICRW. 2000. “Adolescent girls' livelihoods: Essential questions, essential tools-A report on a workshop." New York.
Selim, Mona, et al. 2013. "The Ishraq Program for outof-school girls: From pilot to scale-up.” Final report. [In English and Arabic.] www.popcouncil.org/uploads/ pdfs/2013PGY_IshraqFinalReport.pdf.

Sewall-Menon, Jessica and Judith Bruce. 2012. "The cost of reaching the most disadvantaged girls: Programmatic evidence from Egypt, Ethiopia, Guatemala, Kenya, South Africa, and Uganda." New York: Population Council.

Sinclair, Jake, et al. 2013. "A self-defense program reduces the incidence of sexual assault in Kenyan adolescent girls,"Journal of Adolescent Health 53(3): 374-380.

Smith-Brake, Julia and Veronica Torres. 2012. "Lessons learned of pilot financial literacy project for adolescent girls in Haiti," Making Cents International, May, p. 16.

Soler-Hampejsek, Erica, Christine A. Kelly, Barbara S.Mensch, Paul C. Hewett, Monica J. Grant. 2013. "Retention of literacy and numeracy in rural Malawi: A longitudinal analysis." Paper presented at the 57th Annual Conference of the Comparative and International Education Society, New Orleans, LA, 10-15March.

Soler-Hampejsek, Erica, Christine A. Kelly, et al. 2014. "Gender differences in the retention of literacy and numeracy in Malawi." Poster presented at Annual Meeting of the Population Association of America. Boston, 3 May.

Sommer, Marni, Anan Ackatia-Armah, et al. 2014. "A comparison of the menstruation and education experiences of girls in Tanzania, Ghana, Cambodia, and Ethiopia," Compare: A Journal of Comparative and International Education 44: 1-21.

UNICEF. 2000. "Domestic violence against women and girls." Innocenti Research Centre.

--_. 2002. "Adolescence: A time that matters." New York. http://www.unicef.org/publications/files/pub_ adolescence_en.pdf.

-_-. 2014. "Hidden in plain sight: A statistical analysis of violence against children." New York.

UNICEF Innocenti Research Centre. 2008. "Platform for Action: Towards the Abandonment of Female Genital Mutilation/Cutting (FGM/C)." www.iom.int/jahia/ webdav/shared/shared/mainsite/projects/documents/ platform_for_action.pdf. 
WHO. 2004. "Substance use problems in developing countries." Bulletin of theWorld Health Organization $82(9)$.

Women's Refugee Commission. 2012. "In search of safety and solutions: Somali refugee adolescent girls at Sheder and Aw Barre Camps, Ethiopia." womensrefugeecommission.org/component/zdocs/ download/847

Mourtada, R., Schlecht, J., \& DeJong, J. (2017). A qualitative study exploring child marriage practices among Syrian conflict-affected populations in Lebanon. Conflict and health, 11(1), 53-65. 